\title{
The impact of population, health, and environment projects: A synthesis of evidence
}

\author{
Rachel Winnik Yavinsky \\ Carolyn Lamere \\ Kristen P. Patterson \\ Jason Bremner
}

Follow this and additional works at: https://knowledgecommons.popcouncil.org/departments_sbsr-rh

Part of the Demography, Population, and Ecology Commons, Environmental Public Health Commons, Family, Life Course, and Society Commons, and the International Public Health Commons How does access to this work benefit you? Let us know!

\section{Recommended Citation}

Yavinsky, Rachel Winnik, Carolyn Lamere, Kristen P. Patterson, and Jason Bremner. 2015. "The impact of population, health, and environment projects: A synthesis of evidence," Working paper. Washington, DC: Population Council, The Evidence Project. 


\section{The Impact of \\ Population, Health, and Environment Projects: A Synthesis of the Evidence}

Rachel Winnik Yavinsky Carolyn Lamere Kristen P. Patterson Jason Bremner

June 2015

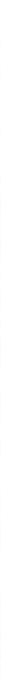





\section{The Impact of Population, Health, and Environment Projects: A Synthesis of the Evidence}

Rachel Winnik Yavinsky, Policy Analyst, Population Reference Bureau Carolyn Lamere, Program Associate, Population Reference Bureau Kristen P. Patterson, Senior Policy Analyst, Population Reference Bureau Jason Bremner, Program Director, Population, Health, and Environment, Population Reference Bureau

June 2015 


\section{The Evidence Project}

Population Council

4301 Connecticut Avenue, NW, Suite 280

Washington, DC 20008 USA

tel +12022379400

evidenceproject.popcouncil.org-

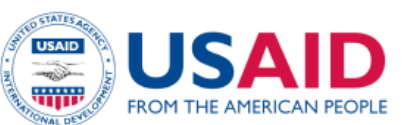

The Evidence Project is made possible by the generous support of the American people through the United States Agency for International Development (USAID) under the terms of cooperative agreement no. AIDOAA-A-13-00087. The contents of this document are the sole responsibility of the Evidence Project and Population Council and do not necessarily reflect the views of USAID or the United States Government.

Published in June 2015.

Suggested citation: Yavinsky, Rachel Winnik, Carolyn Lamere, Kristen P. Patterson, and Jason Bremner. 2015. "The Impact of Population, Health, and Environment Projects: A Synthesis of Evidence," Working Paper. Washington, DC: Population Council, The Evidence Project.

Photo credit on cover page: Antoine Rougie, Blue Ventures

(C) 2015 The Population Council, Inc. 


\section{Table of Contents}

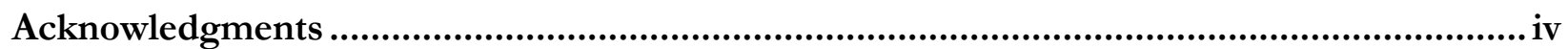

List of Acronyms …...................................................................................................

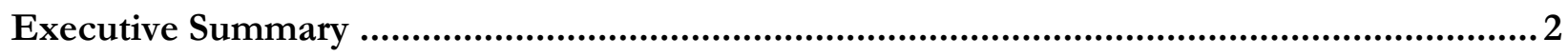

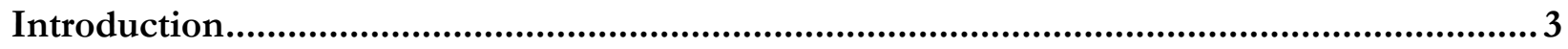

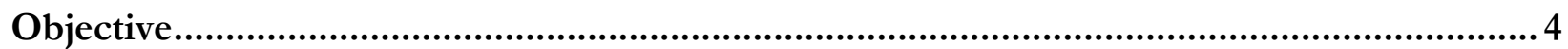

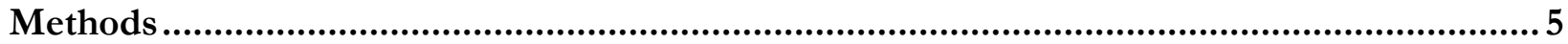

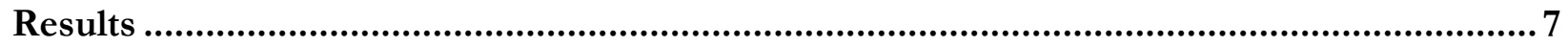

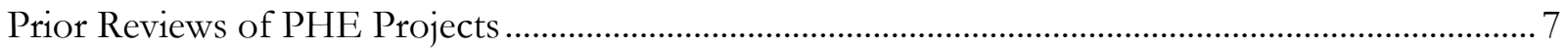

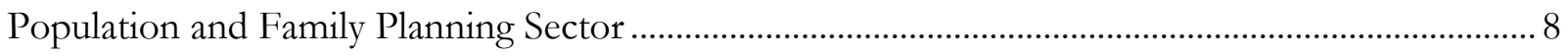

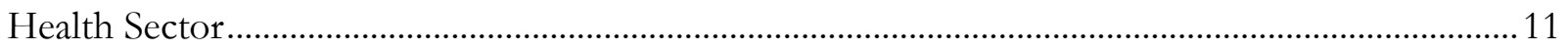

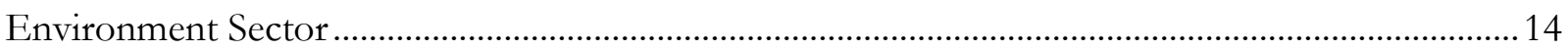

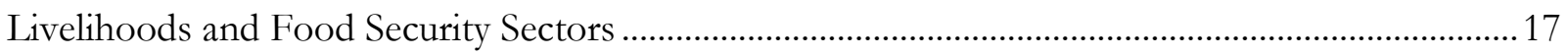

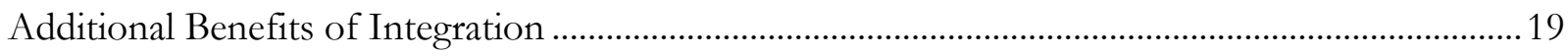

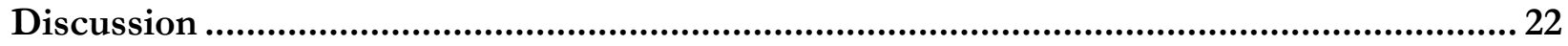

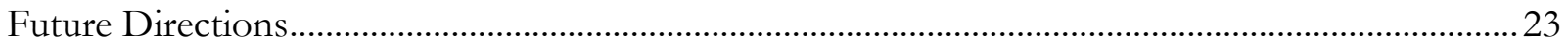

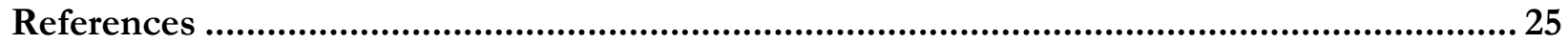

Appendix 1: Evidence of Population, Health, and Environment Changes by Project ...........31 


\section{Acknowledgments}

This publication was authored by Rachel Winnik Yavinsky, Carolyn Lamere, Kristen P. Patterson, and Jason Bremner of the Population Reference Bureau (PRB). We are grateful to Karen Hardee, Director of the Evidence Project, and Clive Mutunga, Family Planning and Environment Technical Advisor USAID, for the initial idea and encouragement to undertake this report and for reading and helping us to improve numerous drafts. Many thanks as well go to Ellen Weiss of the Evidence Project for her edits, ideas, and communications expertise and to Anneka Van Scoyoc of the Evidence Project for making the report, images, and appendices so visually effective. Finally, we must acknowledge all of the researchers, advocates, educators, practitioners, and donors who bring PHE to communities and provided PHE results to us. 


\section{List of Acronyms}

$\begin{array}{ll}\text { ARI } & \text { Acute Respiratory Infection } \\ \text { BMU } & \text { Beach Management Units } \\ \text { CI } & \text { Conservation International } \\ \text { CPR } & \text { Contraceptive Prevalence Rate } \\ \text { CTPH } & \text { Conservation through Public Health } \\ \text { DSW } & \text { The German Foundation for World Population } \\ \text { GPSDO } & \text { Guraghe People's Self-Help Development Organization } \\ \text { HIV/AIDS } & \text { Human immunodeficiency virus/Acquired immunodeficiency syndrome } \\ \text { HoPE-LVB } & \text { Health of People and the Environment - Lake Victoria Basin } \\ \text { IPOPCORM } & \text { Integrated Population and Coastal Resource Management } \\ \text { NGO } & \text { Non-Governmental Organization } \\ \text { PHE } & \text { Population, Health, and Environment } \\ \text { RIMS } & \text { Resource Identification and Management Society } \\ \text { SPREAD } & \text { Sustaining Partnerships to enhance Rural Enterprise and Agribusiness Development } \\ \text { USAID } & \text { United States Agency for International Development } \\ \text { VCT } & \text { Voluntary Counseling and Testing } \\ \text { WASH } & \text { Water, Sanitation and Hygiene } \\ \text { WWF } & \text { World Wildlife Fund for Nature } \\ & \end{array}$




\section{Executive Summary}

Integrating family planning into non-health sector development projects has been promoted as a win-win for multiple sectors, leading to both increased access to and use of contraceptives as well as improvements in many other development indicators. Integrated projects are increasingly collecting data to document implementation and impact, but this evidence is often isolated in project reports and not disseminated widely. Advocates, donors, and others interested in these integrated approaches often call for more evidence of impact, and thus there is need to pull together project findings across many integrated projects to assess and better document what is known about the results and benefits of integrated projects and where gaps in the evidence base still exist.

This synthesis report examines and summarizes recent available evidence from integrated Population, Health, and Environment (PHE) projects to document what they are measuring and/or not measuring, assess the current state of PHE project monitoring and evaluation, and identify gaps in evaluation and research for current and future PHE projects to improve upon. Forty-three documents from 35 projects were reviewed in conducting this synthesis. While some projects began as early as 1992 or as late as 2010, the majority began programming in the early- to mid2000s. A full list of projects can be found on page 7 and in Appendix.

This report analyzes the available documentation assessing integrated programming's effectiveness at implementing complimentary interventions in the well-established fields of population, health, and the environment. It explores the documentation available from projects across different sectors and thus gives a sense of the current state of monitoring and evaluation within PHE projects. Findings from the synthesis suggest that projects report data and impact in some areas, particularly family planning, consistently. The findings, also point out that many PHE projects have found it challenging to collect data and thus document their impact in other sectors, particularly related to their environmental and livelihood programming.

Additionally, the report looks at the evidence surrounding the added value of integrated programming as compared to single sector programming, and suggests ways to improve documentation of the ways that integration provides added value. Finally, this synthesis assesses what evidence could be collected and used to better align projects with emerging fields of interest such as sustainable livelihoods, resilience, and climate change adaptation. This synthesis thus highlights both successes in collecting evidence of the benefits of integrating FP into non-health sectors as well as the challenges of documenting the benefits of integration. Together these successes and challenges point to where stronger evidence is still needed to support the field as a whole. 


\section{Introduction}

Integrated programming to address both social and environmental challenges dates back to the mid-1980s, when integrated conservation and development projects were started. A subset of these programs have employed an integrated approach referred to as Population, Health, and Environment (PHE), aiming to simultaneously improve access to primary health care services, particularly family planning and reproductive health, while also helping communities conserve the critical ecosystems and natural resources upon which they depend. The number of projects explicitly identifying themselves as PHE increased throughout the early 2000s (Hughes 2001). Proponents of such integrated approaches argue that they can be more effective and more efficient than single sector programs for many reasons (Honzak, Oglethorpe, and Carr 2012). Key stated benefits of PHE include (Pielemeier, Hunter, and Layng 2007):

- Increased access to and use of contraceptives by integrating family planning into non-health sector development projects.

- Improved health outcomes, especially in very remote underserved areas.

- Improvements in environment indicators beyond achievements possible in single-sector projects.

- Greater buy in from communities and more rapid mobilization of community efforts, leading to quicker short-term results in the first one to two years of projects.

- Greater involvement in natural resource management activities due to the incorporation of health, livelihood, and micro-credit components.

- Increased access to and involvement of males in family planning and reproductive health.

- Increased access to and involvement of females in conservation and natural resource management activities.

- Time and cost savings both for implementers and communities.

Monitoring and evaluation to measure these and other benefits, however has proved challenging for many programs. The cross-disciplinary nature of integration means that organizations may find themselves implementing programming outside of their traditional areas of focus - a conservation organization implementing a maternal health program, for example - for which they may have limited capacity for evaluation. The breadth and diverse scale of PHE interventions can also make monitoring and evaluation difficult, because the timeframe for results from interventions in different sectors does not necessarily align. For example, some interventions have quick impacts like fully vaccinating children, whereas PHE activities that focus on measuring the environmental impacts of tree planting on the deforestation rate of the wider landscape can take a long time. Additionally, it is difficult to capture the value of "integration" itself due to the nature of complex components which interact with one another, often creating seemingly intangible benefits that are not easily captured through traditional monitoring and evaluation (Mohan 2014).

As a result of these many challenges, the available research and evaluation documenting the full-range of benefits of integrated PHE programs has been limited to just a few peer-reviewed journal articles and summary evaluation reports from more than a decade ago. Over the last several years, however, results have begun to emerge from a new generation of PHE projects. These PHE projects have had an opportunity to learn from past monitoring and evaluation challenges, and present a new opportunity for documenting the benefits of PHE integration.

Working Paper - 3 


\section{Objective}

This report aims to synthesize the existing research and results from projects that integrate family planning with environment, livelihoods, natural-resource management, and other non-health development sectors. The report synthesizes the published and gray literature on current and past integrated projects and the experiences of implementers to generate a summary of the state of knowledge on integrated family planning and environment projects. Specifically, this synthesis documents what is being measured by integrated projects, the proven benefits of integration, and gaps in the evidence base. Based on this analysis, the synthesis highlights and discusses successes and challenges for documenting the impact of integrating family planning and non-health sector development projects. Moving forward, PHE projects can use the information from this synthesis to identify and fill current gaps in the evidence in order to further build the case for why integrating family planning with sectors such as natural resource management and livelihoods is an effective evidence-based development approach. 


\section{Methods}

This synthesis primarily analyzed monitoring and evaluation reports since 2005 produced by projects for use by donors and the public, as well as reports completed by external consultants, and published papers. Over 60 project documents were identified and reviewed, of which 43 project documents from 35 projects contained both the integration requirements detailed in the following paragraph, as well as some level of results reporting. A complete list of projects and reports can be found in Figure 1 (see next page) and in Appendix 1.

PHE projects have a great variety of interventions and objectives. The 35 projects included in this synthesis report do not all define themselves explicitly as PHE projects, but each reviewed project integrates aspects of population, health, and environment in some way. The projects and sources used for this synthesis were identified through the K4Health PHE toolkit; ${ }^{1}$ the Population Reference Bureau PHE Google map; ${ }^{2}$ submissions and proceedings of the 2013 International Population, Health, and Environment Conference; ${ }^{3}$ and communications with PHE professionals. $^{4}$

Population interventions include family planning and/or reproductive health interventions, and can consist of service delivery, counseling, education, or behavior change communication messaging. The health interventions incorporated in these projects range from HIV/AIDS and maternal and child health services to water, sanitation and hygiene (WASH). The environmental interventions include wildlife conservation, natural resource management, and forest or fisheries protection. Many of the environmental interventions, like sustainable fishing, agriculture, and agroforestry, also aim to have positive impacts on livelihoods and food security. While some projects included in this synthesis focus more resources on one element of PHE than another, all seek some level of integration between sectors.

Past program evaluations of the PHE investments by the David and Lucile Packard Foundation and USAID's Office of Population and Reproductive Health were reviewed as an initial starting point for this synthesis. Results from four projects (Blue Ventures; the Jane Goodall Institute's TACARE project; Integrated Population and Coastal Resource Management, or IPOPCORM; and Integrating Population and Health into Forestry Management Agendas in Nepal, which included the Resource Identification and Management Society (RIMS) and World Wildlife Fund projects in Nepal) come from articles published in peer-reviewed journals. Presentations from the 2013 International Population, Health, and Environment Conference that included project results were used as sources for ten projects. For all of the remaining projects, project reports, results summaries, and other publicly available project documents were gathered and reviewed.

\footnotetext{
${ }^{1}$ https://www.k4health.org/toolkits/phe

2 https:// maps.google.com/maps/ms?oe=UTF8\&client=firefox-

a\&ie $=\mathrm{UTF} 8 \& \mathrm{hl}=\mathrm{en} \& \mathrm{vps}=1 \& \mathrm{svv}=218 \mathrm{a} \& \mathrm{msa}=0 \& \mathrm{msid}=107973977648198179741.0004818 \mathrm{~d} 1 \mathrm{e} 0 \mathrm{fe} 8 \mathrm{fc} 62613 \& \mathrm{dg}=\mathrm{feature}$

${ }^{3}$ http:/ / www.prb.org/pdf14/phe-conference-policybrief-2013.pdf

${ }^{4}$ Linda Bruce, Independent Consultant; Janet Edmund, Conservation International; Mathew Erdman, Independent Consultant; Gladys Kalema-Zikusoka, Conservation Through Public Health; Alice Macharia, the Jane Goodall Institute; Vik Mohan, Blue Ventures; Tricia Petruney, FHI 360; Laura Robson, Blue Ventures; Negash Teklu, PHE Ethiopia Consortium; and Elin Torell, CRC, University of Rhode Island.
} 


\section{FIGURE 1 LOCATION OF PHE PROJECTS INCLUDED IN REPORT}

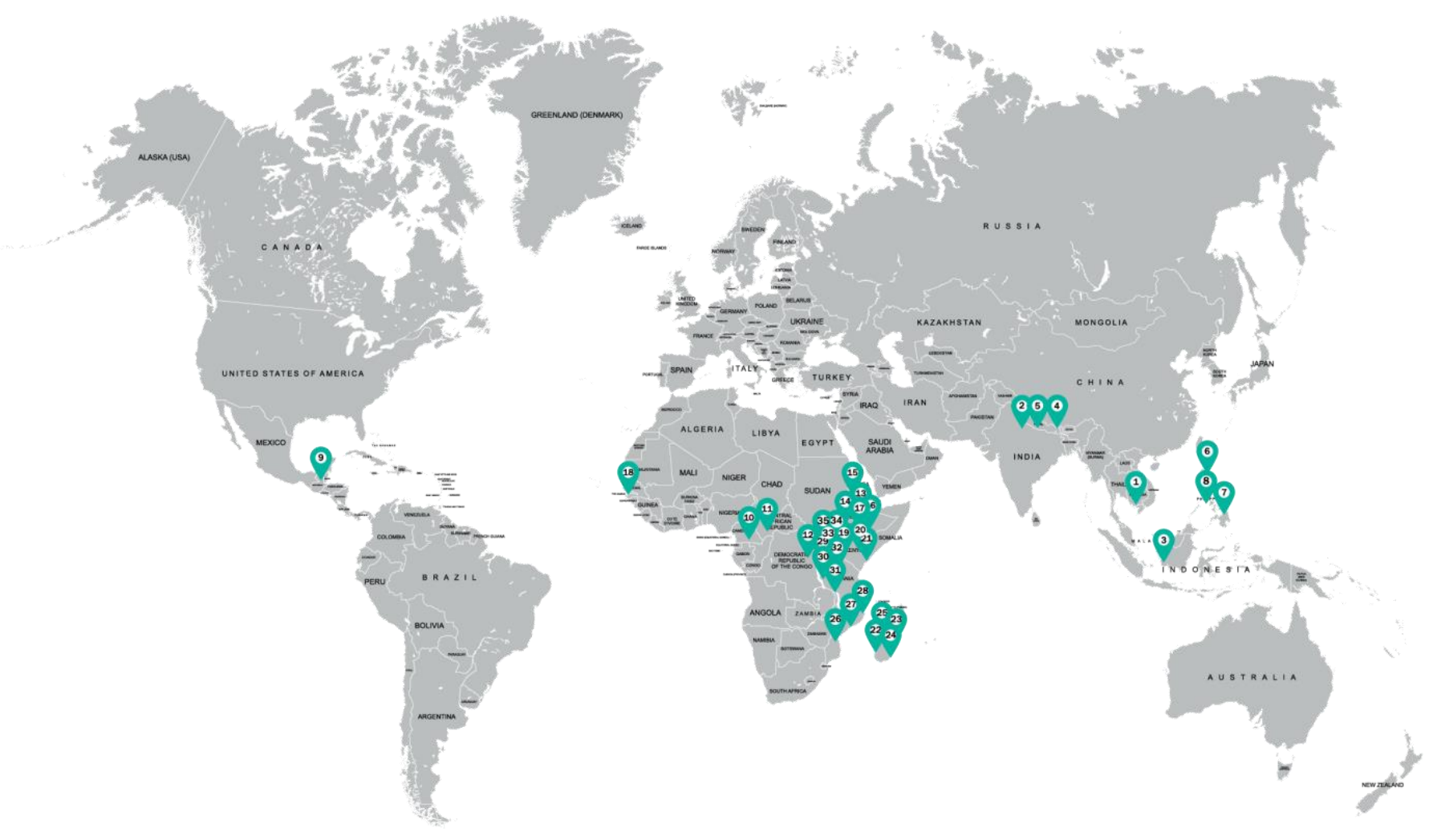

1. Cambodia - Healthy Families, Healthy Forests, CI Cambodia

2. India - Lagga Bagga - India WWF

3. Indonesia - Health in Harmony

4. Nepal - Integrating Population and Health into Forestry Management Agendas in Nepal - RIMS

5. Nepal - WWF - Nepal

6. Philippines - CI Philippines

7. Philippines - IPOPCORM (PATH Foundation Philippines, Inc.)

8. Philippines - Roxas

9. Guatemala - FUNDAECO Guatemala

10. Cameroon - Lobeke, Cameroon WWF

11. Central African Republic Dzanga-Sangha Central African Republic WWF

12. DRC - Jane Goodall Institute DRC

13. Ethiopia - DSW Integrated Bonga Forest Project
14. Ethiopia - EWNRA

15. Ethiopia - LEM Ethiopia

16. Ethiopia - MELCA Ethiopia

17. Ethiopia - Guraghe People's SelfHelp Development Organization (GPSDO)

18. The Gambia - TRY Oysters Women's Association

19. Kenya - Health of People and the Environment in the Lake Victoria Basin (HoPE-LVB)

20. Kenya - Green Belt Movement, Kenya and Land O'Lakes [FHI-360 PROGRESS report]

21. Kenya - Kiunga National Marine Reserve, Kenya - WWF

22. Madagascar - Blue Ventures, Madagascar

23. Madagascar-CI Madagascar

24. Madagascar - Spiny Forest, Madagascar WWF

25. Madagascar - Santénet
26. Mozambique - Gorongosa Restoration Project Ecohealth Program

27. Mozambique - SCIP (Pathfinder)

28. Mozambique - Quirimbas Mozambique WWF

29. Rwanda - USAID SUSTAINING Partnerships to Enhance Rural Enterprise and Agribusiness Development (SPREAD) Project

30. Tanzania - TACARE (JGI)

31. Tanzania - Tuungane

32. Uganda - Conservation Through Public Health (CTPH)

33. Uganda - Health of People and the Environment in the Lake Victoria Basin (HoPE-LVB)

34. Uganda - VEDCO

35. Uganda - Jane Goodall Institute Roots and Shoots Uganda 


\section{Results}

\section{PRIOR REVIEWS OF PHE PROJECTS}

Three past PHE evaluations conducted since the mid-2000s were different than this synthesis in that they evaluated PHE funding initiatives as a whole rather than synthesizing the evidence of impact from each individual PHE project based on their publications and research. The first evaluation, commissioned by the Packard Foundation in 2005, was an assessment of its Population and Environment program, which consisted of a programmatic review of 11 field projects and 45 field sites in five countries, including six projects in the Philippines and Madagascar which were co-funded by USAID (Pielemeier 2005). The assessment was followed by a review of USAID's PHE portfolio in 2007, which focused on nine projects (several of which were also featured in the 2005 assessment), as well as other organizations which supported PHE work by providing technical assistance, analysis of results and dissemination of results, and other activities (Pielemeier, Hunter, and Layng 2007). Both reports noted major barriers to expanding PHE projects, namely: inadequate funding, a limited evidence base, and limited capacity to implement field programs. Since the publication of the 2005 and 2007 assessments, PHE projects have sprung up around the world, and many programs have attempted to collect data on the effectiveness of the integrated PHE approach for development.

A third program evaluation was a 2010 report on the results of Packard Foundation's investments in PHE in Ethiopia, which noted that effective evaluation of PHE projects is constrained by low investments in monitoring, evaluation, and research, limiting the ability to secure future/longer term funding. The report also noted that the short timeframe of many PHE projects is not adequate to learn about PHE, design a project, implement interventions, and report significant results.

An additional analysis conducted in 2011, examined eight conservation projects that included family planning programming to identify evidence of links between family planning interventions and conservation outcomes (Honzak and Oglethorpe 2011). The authors examined three hypothesized pathways through which family planning could improve conservation outcomes, including: "decrease in human fertility," "increase in women's empowerment," and "increases in trust, goodwill, and entry points for conservation." The authors found strong evidence of conservation projects successfully implementing family planning interventions and increased use of family planning. The authors concluded, however, that there was little evidence collected to support the other pathways and recommended more systematic measurement of outcomes related to women's empowerment and support for conservation.

More recently, in November 2013, the Second International Population, Health, and Environment Conference convened in Addis Ababa, Ethiopia. ${ }^{5}$ The conference built on the existing momentum in the PHE community and developed strategies for scaling up efforts to address the priorities of remote and rural communities where poor reproductive health outcomes and population growth exist hand-in-hand with poverty and unsustainable natural resource use. A summary brief of the conference highlights several of the remaining gaps and challenges for PHE

\footnotetext{
5 The first international PHE conference was held in Addis Ababa, Ethiopia in 2007. There have also been national PHE conferences that included many international participants, including conferences held in Kigoma, Tanzania in 2005 and Cebu, Philippines in 2006.
} 
implementers. One gap identified by conference participants was a lack of documentation regarding the benefits of PHE integration, just as was observed eight years ago (Pielemeier, Hunter, and Layng 2005).

The three evaluations and recent conference all share a common call for further documentation of the benefits of PHE integration. In response, this synthesis looks at the most recent generation of PHE projects (circa 2007 to the present) and highlights and discusses successful practices and challenges for measuring and evaluating integrated

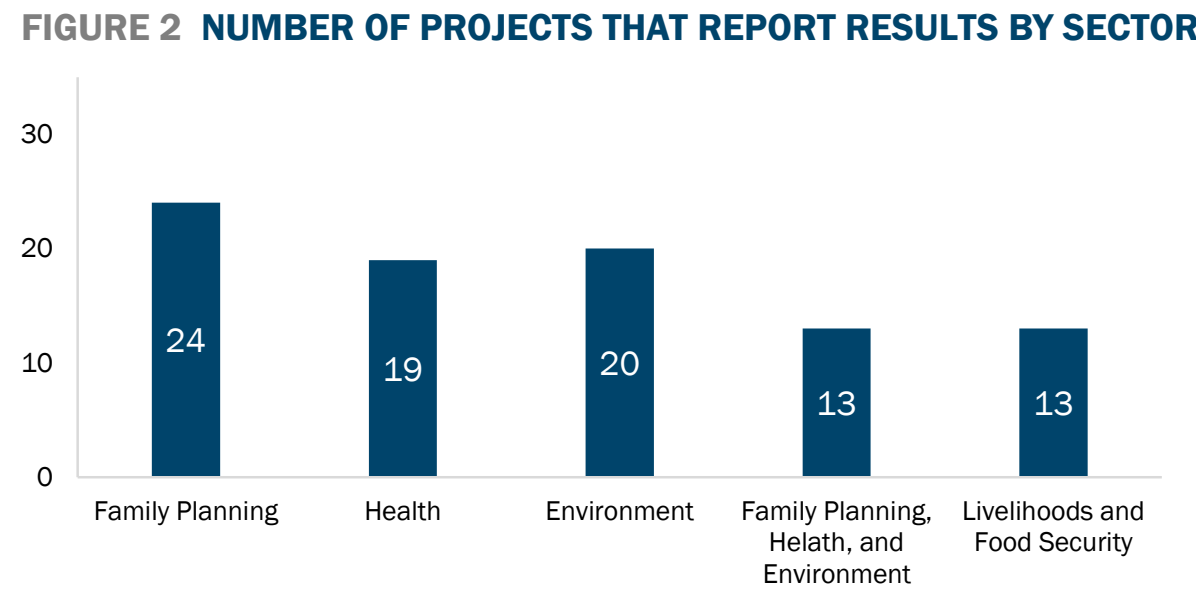

family planning and nonhealth sector development projects. The following sections review PHE program evidence by sector: population and family planning, health and nutrition, the environment, and livelihoods and food security. Figure 2 shows the number of projects we analyzed that report results by sector.

\section{POPULATION AND FAMILY PLANNING SECTOR}

\section{PHE programs, population growth, and reduction of long-term pressures on the resource base}

Despite its source as the "P" in PHE, and many projects' theory of change focusing on reducing long-term pressures on the resource base through slower population growth, few projects actually measure changes in population size or growth rates. Instead, projects focus on access to, use of, and support for voluntary family planning within communities. The PHE projects we examined promote voluntary family planning, and use a rights-based approach designed to help women and couples achieve their reproductive goals. Yet they don't usually include demographic indicators related to population in their monitoring and evaluation efforts. Furthermore, few PHE projects operate long enough or collect sufficient data to conclude whether the family planning and reproductive health programming contributes to declining fertility and long-term slowing in population growth rates. Notable exceptions include the IPOPCORM project in the Philippines, which reported a significant decrease in parity (mean number of children born) among project beneficiaries (D’Agnes 2010), as well as the Blue Ventures project which reported a decline in crude birth rates, an indicator that they are able to track because they take a full census of the communities they work in each time they do impact evaluations. With "population" as one of the central themes and framing for most of these projects, the limited evidence base for impacts on population indicators such as parity, total fertility, and population growth, suggests a gap between project communication and framing and the existing evidence base.

\section{Family planning information, knowledge, and use}

Family planning is an essential component of PHE programming. Data on family planning are among the more consistently reported indicators for PHE programs, and indicators like contraceptive prevalence rate (CPR) or 
number of people counseled on family planning methods are also fairly simple to calculate. Every program included had some kind of family planning intervention, and most used contraceptive uptake as their key indicator. Projects reported this information differently, with some measuring CPR, others couple years of protection, and others measuring unmet need. Twenty-three of the 35 projects reviewed reported data indicating some type of increase in family planning use, of which a selection are included below.

One key question for PHE programs to answer is whether family planning as part of integrated programming is as effective in achieving results as programs focusing solely on family planning alone. Other questions addressed in the synthesis are whether non-family planning organizations can effectively implement family planning programming, whether PHE programs offer any additional family planning benefits that family planning-only programs do not, and whether PHE programs actually slow population growth and reduce long-term pressure on the resource base upon which communities depend. Many PHE programs report increases in contraceptive prevalence. The means of measuring this increase differs between projects: many report CPR; others report couple-years of protection or total number of new users. The most dramatic impacts are seen in very remote areas that had little prior access to family planning. For example, Blue Ventures, a marine conservation organization in southwestern Madagascar, has integrated reproductive health initiatives into their conservation activities. Since adding family planning activities, CPR rose from 10 percent before the project began in 2007 to 55 percent by 2013 (Mohan et al 2013, unpublished data). Another integrated project with sites in Uganda and Kenya, Health of People and the Environment - Lake Victoria Basin (HoPE-LVB), reports 16,944 new family planning clients between a baseline survey in July 2012 and a midterm review in December 2013 (HoPE-LVB 2014).

Additionally, a number of projects, while not reporting contraceptive use data, do report data on other elements of family planning such as increased knowledge of family planning, changes in attitude, or changes in the sexual activity of young people. For example, The Guraghe People's Self-Help Development Organization (GPSDO) dramatically increased the number of men who supported family planning from 7.3 percent to 30.2 percent (GPSDO 2012). Another example is from FHI 360's PROGRESS Project, a USAID family planning operations research project implemented from 2008 to 2013, which documented the successful training of women volunteers from the Kenyan environmental organization the Green Belt Movement, an internationally recognized tree planting and women's empowerment group in Kenya. PROGRESS worked with Green Belt Movement's tree planting groups to provide critical information about the importance of birth spacing, family planning methods, and the importance of delaying childbearing until after age 18. These and other programs, while not directly reporting increased contraceptive uptake, are helping make contraceptive use more acceptable and increasing information and referral sources for family planning. Finally, while all projects considered in this report are in fact conducting some programming on family planning, many did not report specific data or results. For the projects that are already collecting family planning data, baseline data collection along with periodic measurement helps to illustrate trends and changes attributable to PHE, and will help to ensure sustained support from the family planning donors who have been critical supporters of PHE over the last two decades. For those that are not reporting data, collecting further data and communicating family planning impacts will help bolster the already

robust evidence base which demonstrates that family planning interventions can be quite successful as part of integrated programs.

\section{Integration of family planning by non-health and environment organizations in their projects}

Project participants and beneficiaries report that communities welcome the integration of family planning messages into programming related to health, natural resources, and livelihoods. In fact, reproductive health services are 
often among the top health priorities of people in remote regions like the highland forests of Madagascar (Mogelgaard and Patterson 2006).

For example, the PROGRESS project partnered with two existing environment and agriculture organizations in Kenya. PROGRESS worked to add a family planning component to these programs, and collected data on community acceptance of the approach and project outcomes. Intervention evaluations found that integrating family planning into the development projects is both feasible and acceptable to organizations and communities (FHI 360/PROGRESS 2013 and Hoke et al 2015). PROGRESS worked with the Kenya Dairy Sector Competitiveness Program, an agriculture project implemented by Land O'Lakes International Development, to integrate health camps focusing on women's health and include family planning into their regular "farmer field days." More than 80 percent of the 2,344 attendees at the field days received health consultations. Of the 319 women who participated in a survey during the field days, 60 percent received information related to family planning.

PROGRESS in their collaboration with the Green Belt Movement, also evaluated the feasibility and value of integrating family planning promotion into the activities led by the organization's community-based environmental workers, known as Green Volunteers. Almost all of the Green Volunteers reported favorable attitudes about promoting family planning, and all said they were interested in continuing these activities. Communities also reported positive reactions to the integration, both in terms of positive attitudes and increased knowledge of family planning. While the family planning components of these projects ended when PROGRESS project support ended, the experiences of these highlight how an integrated, multi-sector approach can improve family planning access in tandem with other development goals like environmental sustainability, food security, and poverty reduction. The discontinuation, however, suggests that sustainability of family planning integration efforts remains a challenge when funding streams change and a committed family planning partner is not present to sustain the family planning component.

Results from integrated programs also show that integrated PHE projects can be effective at increasing beneficiaries' understanding and appreciation of the benefits of voluntary family planning. The USAID-funded Sustaining Partnerships to enhance Rural Enterprise and Agribusiness Development (SPREAD) Project (20062011) provided technical assistance to communities working in Rwanda's specialty coffee sector, including an integrated community health component for target farmer groups. A primarily qualitative evaluation of the community health program found that the beneficiaries perceived the program positively and that it successfully increased support for family planning (Kitzantides 2010). Coffee cooperative leaders and members mentioned increased understanding of the importance of family planning, including family-wide health and economic benefits, and health workers reported increased acceptance of family planning and normalization of condom use, as well as a decrease in myths and misconceptions about family planning.

\section{Ability of PHE projects to improve provision of contraception compared to family planning-only approaches}

While numerous integrated projects report increases in contraceptive use from baseline levels, particularly in remote areas that had little or no access to family planning, very few PHE projects reported data allowing for an actual comparison with a family-planning only approach. Two projects compared integrated results to nonintegrated controls and found similar increases in contraceptive use between sites with integrated programming versus sites where only reproductive health activities were carried out. One of these, the IPOPCORM project, 
tested whether there are more improvements in both coastal resource management and reproductive health outcomes by delivering these services in an integrated manner, as opposed to delivering either alone (D'Agnes et al 2010). The results showed a similar change in contraceptive prevalence between the integrated sites and the reproductive health only sites, suggesting that both the integrated and non-integrated interventions were equally effective at increasing contraceptive use.

Similarly, the Guraghe People's Self-Help Development Organization (GPSDO) in Ethiopia integrated conservation and livelihood activities into the organization's reproductive health education and community-based family planning program, and compared results from an integrated PHE project site with a site where they only implemented a reproductive health program (GPSDO 2012). GPSDO found that the contraceptive prevalence rate among 962 married women surveyed was 70.7 percent at PHE sites compared with 73.9 percent at the nonintegrated sites, a non-statistically significant difference. GPSDO did, however, find a statistically significant difference in the percentage of women who want to have more children: fewer women in the PHE sites wanted to have more children (42.7 at the PHE site vs. 68.3 at the non-integrated site), which could show an increased understanding of the relationship between family size and resource allocation among women in the PHE integration site, or a recognition of the opportunity cost of caring for additional children versus pursuing livelihoods activities.

Taken together, the results on contraceptive use from PHE projects demonstrate that integrated projects can be effective at increasing contraceptive use, but more research is needed into whether delivering family planning in tandem with other sectors provides added value that increases the impact of the family planning intervention. For example, do PHE programs offer any additional family planning benefits that family planning-only programs do not: does increased community engagement through the PHE process lead to increased family planning uptake in the long run? While some research documenting the integration of family planning with other health sectors has been conducted in the past, notably in a 2010 literature review (Sebert Kuhlmann, Gavin, and Galavotti 2010), PHE programs help provide evidence about the benefits of integration with non-health sector partners and their activities, a distinct challenge from integration within the health sector. These findings show the value of PHE programming in expanding the reach of family planning programs - often for the first time - in remote areas where health projects traditionally do not operate, but PHE projects should not be expected to outperform family planning-only projects in terms of contraceptive use.

\section{HEALTH SECTOR}

Early reviews suggested the importance of integrating additional health components beyond family planning in building community support for PHE projects (Pielemeier, Hunter, and Layng 2005, Pielemeier 2007, and Packard 2010). For many PHE projects, family planning activities are complemented by primary health care; maternal/child health; HIV/AIDS awareness, prevention, and treatment; and/or environmental health. These activities meet many of the common health needs of people, and when PHE projects include several health components, they are able to address a wider range of health issues. Furthermore, since most PHE projects are implemented in remote areas, they often initiate and/or improve community-based delivery of basic and reproductive health services.

In addition, because environment initiatives such as reforestation can take years of investment before showing measurable dividends, some PHE projects report that health activities can help to achieve quick tangible results. Thus, health activities, allow community members to reap the benefits of integrated projects more clearly than projects focused solely on environmental conservation. A good example are the interventions focusing on 
vaccination, de-worming, and water, sanitation, and hygiene (WASH), which are relatively inexpensive to implement and produce quick wins. The impact of these diverse health efforts, however, has not been systematically summarized in past evaluation reports. Here we look at some of the most critical questions concerning these complementary health activities.

\section{Maternal and child health}

Seven of the projects reviewed reported child immunization activities. For example, Health in Harmony, a project based in Indonesia, increased rates of child immunization from 63 percent to 84 percent in the first five years of the project. Along with other child health interventions, this project resulted in statistically significant decreases in diarrhea, fever, cough, and weight loss among children in the project area according to surveys conducted in 2007 and 2012. Another PHE project implemented by the World Wildlife Fund for Nature (WWF) in the Central African Republic vaccinated approximately 50 percent of children in the project site, after which locals, "seeing the positive effects and, importantly, the absence of negative effects," were more open to future vaccination campaigns (Carr 2008).

Maternal and child health interventions are often incorporated into PHE projects because of their natural overlap with family planning and reproductive health interventions and because of the high demand for such services in the remote communities where PHE projects customarily operate. Ten projects reported increases in facility deliveries and other behaviors that suggest increased acceptance of formal maternal health services. One such project is MELCA-Ethiopia, which reported a facility-based delivery increase at the Mio Village project site from 15 percent to 41 percent between 2012 and 2013 (Refera and Belay 2013). Similarly, in Mozambique, the Gorongosa Restoration Project reported a decrease in home births from 84 percent to 49 percent (Clemente 2013). Although most programs have not collected data for long enough to record long-term health impacts, these positive behavior changes may lead to reduced maternal morbidity and mortality.

One common intervention which clearly links health and the environment is the promotion of improved cookstoves, which are designed to reduce community use of forests for fuel and decrease the incidence of acute respiratory infections, the leading cause of death among children in the developing world (World Lung Foundation 2014). RIMS in Nepal focused on a combination of improved cookstoves which use less wood fuel and produce less smoke, and alternative cook stoves that use gas which burns more cleanly than the wood used in traditional stoves. They reported a significant decrease in acute respiratory infections (ARIs), which are linked to indoor air pollution from traditional stoves. The project found ARI incidence in children under five decreased to 301 children compared to 690 children who had ARIs two years before programming began. Furthermore, only 5 percent of cases needed referral for further treatment compared to 55 percent two years prior. The declining trend in ARI was inversely proportional to the uptake in clean energy use, which increased from 22 percent to 40.5 percent of households in 2.5 years (Hahn, Anandaraja, and D'Agnes 2011), making this an excellent example of a linked environmental and health outcome.

\section{Water, sanitation, and hygiene}

Frequently reported health-related results focused on WASH activities, likely because of the close relationship between WASH, the environment, and health: for example, healthy forests capture and store precipitation, which then supplies more ample water to springs and streams for use by people, wildlife, and crops. The rural poor - the intended recipients of most PHE projects - are often more likely to use poor WASH practices than their urban or wealthier counterparts. For example, although only 40 percent of the Mozambican population practices open 
defecation, it is practiced by 96 percent of the poorest inhabitants of rural areas (A Snapshot of Progress 2014). Improved sanitation facilities such as latrines reduce morbidity from diarrhea by about 37 percent, washing hands with soap at critical times by about 35 percent, improving water supply sources (such as enclosing springs) by about 20 percent, and treating water at point-of-use by 45 percent (Facts and Figures 2014).

Eleven projects reported building latrines, constructing or protecting fresh water sources, and educating communities about sanitation, many of which reported improved health behaviors. In Uganda, for instance, Conservation through Public Health reported a 50 percent increase in hand washing facilities, cleansing materials, clean water storage, and drying racks (Kalema-Zikusoka et al 2013). In Indonesia, Health in Harmony reported a 22 percent increase in access to latrines. Additionally, due to education campaigns, defecating in the river decreased by 37 percent, and boiling water before drinking increased by 25 percent (Health in Harmony 2012). Although most projects only report the process and behavior change indicators, some of these interventions resulted in positive behaviors that translated into improved health outcomes, such as reduced incidence of diarrheal diseases. In Nepal, the Terai Arc Landscape project reported that, due to their WASH interventions, no new diarrheal cases occurred following the year's floods (Carr 2008). And, a WWF PHE project in Cameroon reported a decline in diarrheal cases among children from 7 percent to 1.7 percent in the four months following the construction of 250 pit latrines (Carr 2008).

\section{Nutrition}

Despite the existence of long standing standard nutrition indicators, no projects reported directly on nutrition outcomes like the incidence of stunting or malnutrition among children (WHO Child Growth Standards 2006). Instead, project results tied to nutrition focus on household level livelihood measures like improved fish-catch or increased agricultural productivity. Projects also do not appear to be using standardized tools developed for measuring food security at the household level including household expenditure surveys, largely because they are expensive and complicated to implement, unknown to many of the PHE implementers, and because they don't accurately capture the other health and environment aspects of the project. A 2015 review of programs that integrate family planning with food security and nutrition similarly found much variation in the indicators reported for nutrition and food security (FANTA 2015). The failure of PHE projects to employ standard indicators to measure improvements in nutrition does not mean, however, that projects did not contribute to improvements in food security and nutrition. Rather, it suggests an opportunity to improve project measurement.

\section{Value added for the health sector}

Evidence from several projects suggests that the integration of health components with environment programs provides added value for the health aspects of the projects, including family planning. Providing health services alongside conservation activities can help increase access to health services, either by reducing the stigma of the services (like testing, counseling, and treatment for HIV/AIDS), or by making services more accessible. For example, in Rwanda SPREAD reported that placing mobile HIV/AIDS Voluntary Counseling and Testing or VCT services near harvest spots during harvest increased VCT participation by saving beneficiaries' time and reducing the stigma of getting tested (SPREAD 2010). Four other PHE projects reported results for HIV/AIDS activities, ranging from increased use of VCT services to increased mothers and infants receiving preventative drug treatment to stop mother-to-child transmission of HIV. Other projects, like the environmental stewardship organization TRY Oyster Women's Association, have created new entry points to health care. The association trains members of its association in health issues ranging from sexually transmitted infections to malaria to family planning, and encourages women to seek testing for issues like cervical cancer at nearby clinics. These projects did not compare 
results to an area with health-only interventions, limiting conclusions about the performance of the integrated approach versus a single-sector model, but each of these examples illustrates that for the most part PHE projects were providing new services and extending the reach of existing services by either reaching new remote communities or expanding the access points for healthcare.

\section{ENVIRONMENT SECTOR}

Many PHE projects report changes in environmental behaviors among households as well as changes in management practices by communities and user groups such as reductions in slash and burn agriculture, less destructive fishing practices, and demarcations of new protected areas. PHE programs have adapted their environment approaches to the local context - for example, programming approaches which work well in coastal villages may not be as effective in the forest, and different communities have different concerns when it comes to issues like agriculture, poaching, and natural resource management. The range of methods of integrating environmental concerns into programming demonstrates that the effectiveness of PHE programs is not limited to just coastal or forest communities - PHE programs can be tailored to fit the needs of a given community.

Few PHE projects, however, are collecting different types of ecological data to document the impact of the behavioral and management changes on the actual environment. There are likely multiple reasons for this scarcity of environmental data. First, PHE projects, like many community based conservation and environment projects focus on household-level and community level natural resource management interventions rather than large-scale landscape impacts. Thus, some standard techniques like analysis of satellite imagery to measure changes in forest cover are rarely considered applicable even though newer satellite images and aerial photography can measure change at a very small scale. A second challenge is that collecting environmental data requires specific expertise that is often outside the knowledge and experience of most PHE project staff. PHE project staff rarely connect to local experts in ecological data collection who could be contracted to assist projects or to collect and analyze the data, and furthermore there is often a scarcity in local expertise in comparison with standard social survey techniques.

A third reason is that many of the environmental impacts of behavioral and management changes, such as regeneration of fish stocks or improved forest cover, are only visible over long periods of time. As such, PHE projects, like most community-based conservation projects, often do not collect data on environmental impacts because they show little change during the short time scale of projects. This does not mean that the projects will not have long-term impacts it just suggests that some ecological impacts won't be clearly measureable until well after the funding cycle and main activity of a project (Salafsky and Margoluis 1999).

Despite all of these challenges, there are several projects that have collected ecological data and demonstrated the environmental impact of PHE efforts, and these exceptions, described in the sections below, suggest an opportunity for PHE projects to better document the evidence of their impact on the environment.

\section{Population pressure and the environment}

Proponents of PHE advocate for integrating voluntary family planning into environmental conservation and natural resource management as a means of boosting conservation intervention impacts while simultaneously improving health. One PHE assumption is that providing access to family planning will ultimately result in longterm reductions in the total number of resource users, thus reducing pressure on natural resources. While research on the impacts of population growth on deforestation exists (e.g. Harper et al 2007; Sussman and Ratkozafy 1994; Gorenflo et al 2011; Bradshaw and Brook 2014), most projects do not measure the baseline environmental 
resource base (e.g. percent forest cover) nor the size of the population using the resources. In addition, while projects are framed in terms of population-environment links, slower population growth and reduced pressure on resources is a long-term impact that is unlikely to be tangibly measured or noticed in the short-time scale of PHE projects. Furthermore, local, small area data on both population and environmental is scant, making such measurements and documentation a challenge. While PHE projects are unlikely to be able to collect quantitative evidence to document this perceived long-term benefit, qualitative interviews with community members over time could be used to better assess perceived changes in the environment and attribution to reductions in population pressure.

\section{Community-based natural resource management: forests and fisheries}

Several projects focus on reducing deforestation. A number of projects have successfully introduced alternative cookstoves - either more fuel efficient wood stoves (known as improved cookstoves) or biogas stoves. Both types of cookstoves reduce the amounts of wood needed by households in comparison with traditional cookstoves and benefit human health as discussed earlier. The WWF project in Nepal, for example, installed 120 improved cookstoves and 130 biogas-fueled stoves, saving a total of 715 metric tons of firewood. The RIMS Nepal project focused on biogas stoves; over 40 percent of households used these stoves in 2009, compared to just 22 percent at the baseline three years earlier. The project estimates that a total of 3,583 metric tons of firewood were saved as a result. Other projects report similarly impressive results in Asia: the Terai Landscape Arc in Nepal saved 225 metric tons of firewood; a WWF project in Lagga Bagga, India reported a 60-70 percent reduction in firewood collection, and Health in Harmony in Indonesia recorded a nearly 40 percent drop in wood use.

Many projects illustrate success with agroforestry, tree nurseries, and reforestation programs. The FUNDAECO project in Guatemala reports the reforestation of 783 acres of land, for example, and a Conservation International (CI) project in the Philippines reported 1,620 hectares reforested with fruit trees, and 196 hectares of agroforestry farms developed (FUNDAECO 2011; Conservation International 2008). The impact of these PHE projects' efforts to improve forest cover in the project areas, however, have not been measured or reported as actual changes in forest cover using standard satellite imagery measurement tools. This is in part because reforestation efforts take a long time to show results as any improvements in forest cover require planted trees to grow and mature. Furthermore, while important for reducing forest loss and improving health, household fuel use for cooking is not the only cause of deforestation - cutting trees, making charcoal, and selling it for use in urban markets is a key driver of deforestation in many countries, such as Uganda and Zambia (Vinya et al 2011).

Most integrated projects focus on community management of natural resources and individual behaviors that negatively affect the environment. A commonly measured impact in several projects is a reduction in destructive fishing behavior. For example, the HoPE-LVB project promoted the protection of community resources that allowed for natural restocking of fish through the establishment of 16 fish breeding sites which are demarcated and patrolled by community beach management units (HoPE-LVB 2014). A WWF project in the Kiunga National Marine Reserve in Kenya, on the other hand, focused on changing community fishing techniques. By 2007, 100 percent of registered fishermen in the reserve used sustainable fishing methods instead of illegal fine-meshed nets which deplete resources of young fish, up from 89 percent at baseline in 2004 (Carr 2008). In the Philippines, IPOPCORM targeted multiple behaviors by reducing use of damaging fishing methods such as cyanide and dynamite and by diversifying livelihoods so that households relied less heavily on fishing for subsistence. In their integrated site, the IPOPCORM project found a statistically significant reduction in the proportion of households dependent on fishing, and community members were less knowledgeable about destructive fishing techniques in 
their area, which could indicate a decrease in the use of such practices. This same trend was not found at the sites which had only an environmental intervention (D'Agnes et al 2010).

At the local level, some communities collect qualitative data from fisherman and communities in which they report improvements in coastal and aquatic natural resources, notably increases in the volume and diversity of fish catch, as well as coral cover and mangroves. Community beneficiaries of the Blue Ventures project in Madagascar perceive the fishery no-take-zones as "highly effective in enhancing catches" (Harris et al 2012). Similarly, beneficiaries of the WWF coastal Quirimbas project in Mozambique, the WWF Kiunga National Marine Reserve project in Kenya, and the HoPE-LVB project in Uganda and Kenya have reported increases in fish volume, diversity, and catch (Carr 2008; HoPE-LVB 2014). There are also a few examples of PHE projects collecting marine resource data to illustrate environmental impact. The Kiunga project reported a 22 percent increase in marine turtle nests recorded by communities, illustrating an efficient technique in which community members themselves participated in monitoring of environmental resources. IPOPCORM, using more complicated and costly methods for data collection, including scuba diving to monitor coral reef health, found a statistically significant increase in coral cover and mangrove volume compared to the environmental interventions-only site (D'Agnes et al 2010). Both of these projects demonstrate that marine resource data can be collected to illustrate the environmental impacts of PHE projects.

\section{PHE projects' goodwill and reductions in human-wildlife conflict}

One common conservation challenge is frequent instances of human-wildlife conflict, which can include destruction of crops by wildlife, wildlife attacks on humans and livestock, and poaching of wildlife by people. Such conflict can result in serious harm to individuals and to livelihoods, and can encourage communities to retaliate, often against endangered wildlife like elephants. Addressing human-animal conflict is critical to protect lives and livelihoods for communities, and to protect animals which live in close proximity to humans.

The Jane Goodall Institute in Tanzania and the Democratic Republic of the Congo and Conservation Through Public Health (CTPH) in Uganda both report success in reducing conflict by involving communities in wildlife patrols and protection and by building community goodwill toward the conservation projects by providing other desired interventions (such as health care including reproductive health), an important advantage that integrated programs have over conservation-only programs. CTPH found that providing health and support for livelihood related activities made community members more eager to support the conservation efforts. Community volunteers participate in Human and Gorilla Conflict Resolution teams who encourage gorillas foraging in community land to move back into protected areas, which limits human-gorilla contact (and potential zoonotic transfer) and prevents gorillas from becoming habituated to raiding human crops (e.g. bananas). The benefits of the integrated project, including increased protection of agricultural lands from gorillas, has led to improved attitudes of communities toward the gorillas, reduced poaching and illegal forest take, increased reporting of incidences of human-gorilla interaction, and better health monitoring of humans, gorillas, and livestock (Conservation Through Public Health 2013; Gaffikin and Kalema-Zikusoka 2010). Some projects, like the Jane Goodall Institute project in the Democratic Republic of the Congo, also actively combat poaching. This project provides salaries, equipment, and food rations for patrols and data about local wildlife and illegal activities, along with support for livelihoods like agroforestry which do not threaten local wildlife.

16- The Impact of Population, Health, and Environment Projects 


\section{CAN FAMILY PLANNING CONTRIBUTE TO RESILIENCE AND CLIMATE ADAPTATION?}

Communities which are heavily dependent on natural resources and have the poorest access to primary and reproductive health care - in other words, those most likely to benefit from PHE activities - are also among the most vulnerable to climate change (PRB 2014, DeSouza 2014). The changing climate can negatively impact communities in a number of ways, from declining fish stock due to ocean acidification, to changing precipitation and temperature patterns which make agriculture more challenging and make extreme weather events like hurricanes, floods, and droughts more common. Integrated approaches to development such as PHE could be part of the solution (Hardee and Mutunga 2009, PRB 2014, DeSouza, 2014).

Historically, PHE programs have focused on biodiversity conservation. More recently, a few PHE projects have begun to consider and incorporate climate change into PHE programs, including resilience and climate change adaptation. Unfortunately, data documenting the impact of these efforts have not yet been collected. In fact, while a clear case can be made for a link between improved access to family planning and improved resilience, more data need to be collected to convince the climate community of the importance of family planning. As more standardized tools become available to measure and apply climate data and resilience at the local level, opportunities exist for PHE projects to use these tools to demonstrate the links between PHE, family planning, and resilience. PHE projects such as the Tuungane (Let's Unite in Kiswahili) project implemented by The Nature Conservancy, Pathfinder International, and the Frankfurt Zoological Society in western Tanzania are beginning to look at how they can increase community resilience to climate change (Pathfinder International 2014). The Tuungane project has in fact prioritized adaptation to climate change, recognizing that accounting for changing climatic conditions is critical for the success of the program. The project also emphasizes the importance of engaging the community in tracking the changes already observed in the project area and creating strategies that are resilient to coming challenges like shorter growing seasons and reduced water availability (Girvetz et al 2014). Other projects, such as Blue Ventures in Madagascar have consistently measured income and income sources, which can be related to resilience, and have also experienced natural disasters during the PHE project. Households which are healthy and have diversified livelihoods are likely to exhibit more resilience and be better positioned to respond to these complex shocks. Because PHE projects address a number of aspects of resilience, there is an opportunity to work with these PHE projects to better document and measure improvements in resilience that come from integrating health interventions, particularly family planning, with climate adaptation efforts.

\section{Value added for conservation efforts}

Several projects reported that the integrated nature of PHE, particularly the emphasis on family planning, encourages women to get involved in natural resource management, and they are increasingly active in PHE trainings and community meetings. In Madagascar, for example, Blue Ventures uses health clinics both to engage women in conservation work and to allow them to make choices about their sexual and reproductive health (Harris 2011). Other projects reach women through other means; the RIMS project in Nepal offers non-formal literacy classes which are designed to also teach PHE principles, and are mostly attended by women and girls (D'Agnes 2009). In some communities, like those reached by the Terai Arc Landscape project managed by WWF in Nepal, conservation interventions help increase women's empowerment by providing them with leadership opportunities (D'Agnes 2009). Involvement in conservation activities also allowed women in these communities greater freedom to move through their communities with fewer constraints.

\section{LIVELIHOODS AND FOOD SECURITY SECTORS}

Despite not being included explicitly in the PHE acronym, most PHE projects have found that livelihoods and food security are priorities for communities, and are thus a core part of PHE initiatives. In many rural 
communities, livelihoods, food security, and the environment are inextricable, and projects work under the principle that individuals, communities, and the environment all benefit from addressing these issues together. Projects often vary in their approaches to improving livelihoods based on the needs and priorities of communities, the expertise of the organizations, and priorities of funders. Some focus on improving existing agriculture or fishing livelihoods practices, for example by encouraging communities to move away from destructive techniques which negatively impact future livelihoods, like slash and burn or shifting agriculture and the use of cyanide and dynamite in fishing. Others introduce new income-generation activities such as basket weaving. Projects also vary in the ways they measure the impacts of these activities - some count the acres converted to improved agricultural techniques, while others measure changes in fish catch. Because of the varied nature of these interventions, there are few common measures of impact on livelihoods or food security that can be assessed across PHE projects, but data can be readily collected at the household and community level and used by projects to report impact.

\section{Diversification and sustenance of livelihoods}

Projects incorporated a range of livelihoods activities - activities in which individuals and households produced food and/or earned income - in their interventions, which varied based on the needs and priorities of the communities and the suitability of the environment for particular livelihood strategies. Most projects, however, do not use a standard livelihoods approach (e.g. Scoones 1998), or standardized livelihoods measurement tools, which involve careful measurement through household survey data collection of a variety of household assets, household income sources, and levels of income.

The most common livelihoods activities in PHE projects focus on modifying existing livelihoods to reduce harmful impacts on the environment, including promoting sustainable fishing and agricultural techniques. A WWF project in Lagga Bagga, India, for example, trained community members in stall-fed cattle raising, which helped keep cattle from ranging freely and thus preserved the community's forest (Carr 2008). Health in Harmony in Indonesia successfully encouraged community members to substitute sustainable agricultural methods like planting orchards and cultivating wet rice in place of the slash and burn farming commonly practiced in the area (Health in Harmony report). Three hundred community members were trained in organic farming and 400 were trained in tree planting, resulting in a 40 percent increase in wet rice farming and a 31 percent increase in orchard cultivation over the course of the project.

Many projects work with women to develop alternative livelihoods, which help them earn additional income and increase their status within the family and community. For example, in Ethiopia GPSDO found that 57.7 percent of women in the PHE program area earned income through alternative livelihoods, compared to only 15.2 percent of women in communities which only received reproductive health interventions (GPSDO 2012). Similarly, women in the intervention communities of the HoPE LVB project report qualitatively greater economic freedom thanks to livelihood interventions introduced by the project including tree nurseries, selling goods, and sustainable gardening of vegetables around the home (HoPE-LVB 2014). Noticeably absent from the PHE evidence of impact on livelihoods, however, is the use of standard frameworks and tools commonly used to assess household livelihoods, their access to human, social, natural physical, and financial capital, and their diversification into the new and sustainable alternative livelihoods (Scoones 1998). And PHE projects that are actively working on livelihoods and may be having an impact, are not yet documenting changes in levels of income or diversification in the number of income sources as standard practice.

18 - The Impact of Population, Health, and Environment Projects 


\section{Improvements in food security}

Similar to livelihoods, PHE projects also range in their measurement and reporting of food security impacts. For instance, following nearly a decade of program work, the WWF Terai Landscape Arc project staff observed in a 2010 review that one- to two-thirds of women likely had greater food security (Diamond 2010). Other projects, like CI's PHE projects in Cambodia and Madagascar, measured hectares under improved rice production (100 and 520, respectively, up from 0 and less than 100), and interpreted this change as contributing to improved food security (Conservation International 2008). One project in the Philippines, IPOPCORM, used a reduction in household dependence on fishing as a proxy for improved food security. IPOPCORM documented that households in the PHE program area were less likely to be solely dependent on fishing for their income than households in the coastal resources management-only intervention areas, and thus were likely to have greater food security. Finally, another project in the Philippines, run in Roxas by WWF, noted that actual fish yield per hour of labor increased from .07-2.4 $\mathrm{kg}$ to $1-3 \mathrm{~kg}$ over the three years of the project (which may or may not be a proxy for improved food security; it was not specified by the project) (Carr 2008).

Despite these measurement challenges, many projects report the advantages of integrating health messages into food security programming. Santénet, a USAID/Madagascar health project, worked with partners to help farmers earn money, increase food security, and fight malnutrition by introducing orange-fleshed sweet potatoes that are rich in vitamin A: $440 \mathrm{NGO}$ supervisors and farmers were trained on the production of orange-fleshed sweet potatoes and the importance of the high vitamin A content of the new variety (Chemonics International 2008). Santénet also integrated this work with conservation activities, using fruit trees rich in vitamin A to promote reforestation.

\section{ADDITIONAL BENEFITS OF INTEGRATION}

Because few projects conduct research comparing their integrated interventions to single-sector projects in comparable communities, it is difficult to draw conclusions on the added value that integration itself brings to the projects. Evidence gathered for this synthesis, however, suggests that integration does have many benefits for project implementers and beneficiaries.

\section{Increased community support for environmental programming}

Many projects report that integrating community priorities such as health and livelihood activities with natural resource management can increase community support for interventions that may have otherwise been less popular. Conservation activities can sometimes be difficult for communities to accept. This is especially true when the organization coming from the outside is known primarily for conservation activities, like WWF, or when the community experiences serious conflicts with endangered animals in the area, as the communities in Quirimbas, Mozambique encountered with elephants (Carr 2008). Qualitatively, many WWF projects report that before population and health interventions began, communities believed that WWF cared more about the animals than about the well-being of community members (Carr 2008). Blue Ventures in Madagascar has also found that community members see family planning and other sexual and reproductive health services as a "logical natural resources management measure," and also find it is more relevant to their lives (Mohan, Robson, and Savtizky 2013). Thus, health and population activities can increase community buy-in as communities realize that projects are working for the good of communities as a whole, not just the conservation of local flora and fauna. 


\section{Increased male support for and involvement in family planning}

When family planning messages are presented jointly with messages from other sectors, men may be more receptive to them and/or more willing to become involved by using family planning themselves, educating peers, or being supportive of their spouse's use of family planning. Nine of the projects reviewed report increases in men's support for or involvement in family planning. For example, focus groups in the PROGRESS project collaboration with the Green Belt Movement expressed that having the Green Volunteers promote healthy timing and spacing of pregnancies exposed more men to family planning messages, allowed couples to talk more freely about their family planning choices, and motivated some men and women to seek family planning services as a couple (FHI 360/PROGRESS 2013 and Hoke et al 2015). Similarly, male beneficiaries of the SPREAD project in Rwanda reported a "change in mentality" around family planning (Kitzantides 2010). In Ethiopia, GPSDO found a significant difference in the percentage of men who supported use of contraception in PHE sites compared to reproductive health only sites (30.2 percent vs. 7.3 percent); additionally, 53.3 percent of men in the PHE sites reported wanting more children, which is significantly lower than the 70.3 percent in the reproductive health only sites (GPSDO 2012).

\section{Increased women's involvement in environment and natural resource management}

Several projects reported that the integrated nature of PHE, particularly the emphasis on family planning, encourages women to get involved in natural resource management, and they are increasingly active in PHE trainings and community meetings. For example, the HoPE-LVB project in Uganda and Kenya reported a greater number of women participating in beach management units (BMUs) (HoPE-LVB 2014). In Madagascar, Blue Ventures uses health clinics both to engage women in conservation work and to allow them to make choices about their sexual and reproductive health (Harris et al 2011). Other projects reach women through other means; the RIMS project in Nepal offers non-formal literacy classes which are designed to also teach PHE principles, and are mostly attended by women and girls (D'Agnes 2009). In some communities, like those reached by the Terai Arc Landscape project managed by WWF in Nepal, conservation interventions help increase women's empowerment by providing them with leadership opportunities (D'Agnes 2009). Involvement in conservation activities also allowed women in these communities greater freedom to move through their communities with fewer constraints.

\section{Increased resonance with youth}

Many projects actively reach out to youth. For example, the Jane Goodall Institute's Roots and Shoots Uganda project used peer outreach and the donation of school and sanitary supplies to encourage 670 girls to go back to school after previously dropping out, and reduce female absenteeism (Bitarabeho 2013). DSW's Integrated Bonga Forest Project in Ethiopia found that nearly 44 percent of young people in the project area participated in forest management activities, compared to less than 20 percent in the non-project area, suggesting that integrated activities helped get young people excited about conservation (Demisu 2013). Other projects, like SPREAD in Rwanda and IPOPCORM in the Philippines, used peer engagement to spread messages about health and sexuality (Kitzantides 2010; D’Agnes et al 2010). Importantly, IPOPCORM found that a "stewardship" model of health education which tied in conservation ideas was more effective than providing only reproductive health information to young people (D’Agnes et al 2010).

\section{Increased time savings and decreased cost for projects and communities}

While it seems to make sense that integrating activities would at a minimum save projects time and money on transport, social marketing and overhead, few projects have quantified these savings compared to single-sector 
projects. PHE interventions often target rural and remote communities, located far from population centers and health services - traveling the "last mile" to reach communities previously considered inaccessible. In Lagga Bagga, India, for example, communities had little to no access to health care prior to the health camps established by the WWF (Carr 2008). Blue Ventures in Madagascar has found that the remote nature of its PHE intervention sites on the western coast of the country makes integration more feasible than providing separate health and environment interventions, for example by sharing transportation costs as midwives and conservation practitioners travel from village to village (Harris et al 2011). In the eastern forest of Madagascar, from 2004 to 2008 Santénet, a USAID supported project, implemented a community-centered behavior change approach called Champion Communities. In select communities, a PHE approach was taken, where natural resources management and livelihoods activities were integrated into the maternal and child health program, resulting in cost efficiencies and greater results (Santénet 2008).

Some projects are beginning to report quantitative evidence that integrating PHE can be both cost-effective and time-efficient. To begin with, PHE programs are relatively inexpensive since they are typically community-driven and do not require heavy external inputs. For example, a survey of WWF PHE programs found that they cost between $\$ 0.50$ and $\$ 5.00$ per person per year (Carr 2008). Blue Ventures noted that providing family planning services saved families and the public health system $\$ 50,097$ over the three year period of their initial PHE project, because of reduced maternal and infant mortality (Harris et al 2011). Notably, it also found that integrating population and health activities with conservation cost less than implementing each activity separately (Harris at al 2011). PHE programs often draw upon already-existing programs for further savings: the RIMS project in Nepal was able to deliver health messages more quickly and effectively by working with established forest conservation groups (D’Agnes 2009).

Both implementers and beneficiaries of PHE projects continue to report the added value of integration of health, environment, and livelihood activities, and there is strong qualitative evidence to support these claims. Collection of the data to provide quantitative evidence of this added value, however, is both complicated and costly to collect. Projects such as HoPE-LVB and Blue Ventures are looking at alternative means of evaluation to overcome some of the barriers to measuring integration's added value, which may provide future guidance to a next generation of PHE efforts. Currently these efforts are in the planning stage but both projects are working with academics who have expertise in evaluation to identify a combination of further quantitative analysis of existing data along with additional qualitative data collection to assess the process through which PHE integration adds value to the projects. Here again there exists an opportunity to share lessons and insights across multiple projects and test a pilot evaluation approach for better documenting evidence of the added benefits of integrating FP with other nonhealth sectors. 


\section{Discussion}

Evidence from PHE projects shows that these diverse integrated approaches can be successful at addressing many of the PHE and livelihood challenges of communities. Projects collect evidence in different ways and measure different indicators, but the overarching message from the projects reviewed is clear: PHE projects can have a profound impact on family planning use, reproductive health, and other health and environmental practices and behaviors.

Nevertheless, it is also evident that the evaluation of interventions within some sectors is either limited or not consistent with the available evaluation tools in these sectors. Notably, projects could use available standard tools to collect environmental/ecological data and measure environmental impact; incorporate standard livelihoods and nutrition indicators to document improved livelihoods, nutrition, and food security; and help integrate climate change into the projects and measure resilience and adaptation to climate change (Hardee 2014, Scoones 1998). Sustained support for integrated programming depends on an evidence base on all sectors, not just the ones which are most commonly or easily measured.

Additionally, few projects are conducting evaluations comparing integrated projects to single-sector projects, limiting the conclusions that can be drawn about the benefits of integration itself. To encourage funding for integrated projects, programs need to demonstrate that integrated programs enhance their sector-specific activities and messages: for example, including a reproductive health component does not divert attention away from conservation activities. Further implementation science is needed to more clearly outline the benefits of integration itself, which can include cost-savings and efficiency, reaching hard-to-reach and under-served communities, and increasing community buy-in.

Integrating family planning and reproductive health programs with non-health sector interventions is acceptable to communities, engages males and youth, and tends to increase community goodwill toward other aspects of the projects that may not originate as community priorities. This has been most frequently observed by conservation organizations which already had a presence in communities prior to adding family planning and reproductive health components to their programming.

In the rural communities where most integrated PHE projects take place, health and livelihoods are inextricably linked with natural resources and food security. Results from these projects show that addressing livelihoods should be considered an essential part of PHE projects. Additionally, livelihoods are often a top community priority. As has been observed with health and family planning activities, including livelihoods interventions can increase community support for programming whose benefits are longer-term, like reforestation, the establishment of protected areas, and wildlife conservation.

Using integrated messaging linking family planning, health, environment, and livelihoods appears to increase their resonance among men, women, and youth, potentially increasing their involvement and support for activities. However, many of the benefits of integrated programs are highly dependent on the dedication and flexibility of project funding. Projects can only be responsive to community priorities if the funding has some built-in flexibility, so that if a donor decides to shift their funding allocation, the integrated intention of the project can be maintained. 


\section{FUTURE DIRECTIONS}

Evidence from a number of PHE projects shows that an integrated approach can effectively address population, health, livelihood, and natural resource challenges in communities. But there are many additional projects working on PHE-type activities which have not been featured in this report due to insufficient collection, publication, and archiving of data and reports. More data on the full spectrum of PHE activities would assist projects and the PHE community to better communicate the full picture of the benefits of PHE programs and results achieved to date, and could bolster the case for greater investments in individual PHE projects and integrated approaches as a whole. To produce strong evidence, projects should emphasize data collection from the beginning, including conducting baseline research prior to project implementation and developing a strong theory of change so that project focus areas and measures of success are carefully selected and defined. Partnering with organizations with robust experience in monitoring and evaluation in specific fields (e.g. ecological data, forest cover change, or population growth) could help organizations select and apply appropriate field-based evaluation tools.

Additionally, while many projects excel at recording sector-specific data (e.g. vaccination rates, CPR, number of trees planted, and changes in fish catch rates), there are still only a handful of projects that have collected sufficient data to illustrate some evidence of the added benefits of integrated programming. PHE projects are complex and single-sector donors often ask why they should bother investing in something outside of their usual funding priorities? One of the attractive responses to this question is that PHE integration can "add value" to their sector objectives through cost and time savings, reaching new groups and efficiencies, and amplifying impacts of their interventions. PHE projects need to pilot new approaches to document the "added value" of PHE projects, and implementation science can help the PHE community develop these techniques and make their use across projects standard practice. While measuring these outcomes is rarely included in the goals and objectives of PHE projects, it is often used in the justification and proposal writing process. A larger body of evidence will help justify further investments in PHE by existing and new donors. Projects should not embark on costly evaluation of integrated sites vs. comparable single-sector intervention sites using a randomized control trial approach, but rather should explore and pilot alternative evaluation approaches such as realist evaluation ${ }^{6}$ (Pawson \& Tilley 1997, Pawson 2013) with research and academic organizations in order to identify evaluation approaches that could fit within existing monitoring and evaluation budgets.

Further implementation science is also especially critical for PHE projects that are expanding the definition of what constitutes PHE, with the addition of livelihoods, climate change adaptation, and household and community resilience programming. Projects need to learn to use appropriate tools and metrics to measure all of the diverse aspects of PHE program outcomes, and implementation science can help them with the strategic generation, translation, and use of this new evidence to improve their programming in these emerging areas such as family planning and its connections with climate change adaptation and resilience. One clear way to improve the use of implementation science is through more substantive technical assistance partnerships with research and

\footnotetext{
${ }^{6}$ Pawson and Tilley argued that in order to be useful for decision makers, evaluations need to identify 'what works in which circumstances and for whom?', rather than merely 'does it work? The complete realist question is: "What works, for whom, in what respects, to what extent, in what contexts, and how?" In order to answer that question, realist evaluators aim to identify the underlying generative mechanisms that explain 'how' the outcomes were caused and the influence of context.
} 
academic institutions that could provide assistance and data on ecological assessments, livelihoods, climate change adaptation, and resilience, where applicable.

In closing, through this synthesis of evidence it is clear that PHE projects are having an impact on people's lives, improving the health, well-being, and environment of households and communities across diverse settings and landscapes. The evidence documents that PHE has very clear and compelling family planning and other health impacts. Changes in environmental behaviors and management impacts are evident from agricultural plots to forests and fisheries. And there is evidence of efficiencies and added benefits that come with integration. There are however, many opportunities to improve monitoring and evaluation of PHE projects and to use implementation science to develop more robust evidence of the benefits across each sector. Moreover, there is an opportunity to guide a next generation of PHE projects to use standard frameworks and metrics to better link PHE and family planning integration with emerging priorities such as resilience and climate change adaptation. 


\section{References}

“A Snapshot of Progress - 2.14 Update." WHO/UNICEF Joint Monitoring Programme for Water Supply and Sanitation (JMP). http://www.wssinfo.org/fileadmin/user upload/documents/Four-page-JMP-2014-Snapshotstandard-on-line-publishing.pdf

BALANCED Project. 2011. "Research brief: Assessing the benefits of integrating family planning and environmental management activities - Lessons learned from the Philippines.” Narragansett, RI: Coastal Resources Center, University of Rhode Island. p5.

Bitarabeho, Rachel. 2013 "Conservation through health: A case study of the Jane Goodall Institute's peer education programme in Uganda." The Jane Goodall Institute, Uganda, presented at the $2^{\text {nd }}$ International Population, Health, and Environment Conference, November 2013.

Bitarabeho, Rachel. 2013. "A case study of the Jane Goodall Institute's peer education programme in Uganda." Presented at the 2013 Population, Health, and Environment Conference, November 11-13, 2013.

Bradshaw, Corety J.A. and Brook, Barry W. 2014. "Human population reduction is not a quick fix for environmental problems." Proceedings of the National Academy of Sciences.

Carr, David. 2008. “An evaluation of WWF's USAID and Johnson \& Johnson supported projects.”

Castro, Joan Regina, Leona Ann D’Agnes, and Carmina Angel Aquino. 2004. "Mainstreaming reproductive health and integrated coastal management in local governance: The Philippines experience." Coastal Zone Asia-Pacific Conference.

Cerezo, Marco, Karen Dubois, and Quetzalí Cerezo. 2014. “Conservation of the biodiversity based on women’s empowerment: Community health clinics for women in protected areas.” FUNDAECO, Guatemala.

Clemente, Corina. 2013. "Improving community health in the buffer zone of Gorongosa National Park." Gorongosa Restoration Project Ecohealth Program. Presented at the 2013 Population, Health, and Environment Conference, November 11-13, 2013.

D’Agnes, Leona et al. 2010. "Integrated management of coastal resources and human health yields added value: a comparative study in Palawan (Philippines).” Environmental Conservation. 37(4): 398 - 409.

D’Agnes, Leona. 2009. “The population, health and environment (PHE) pathway to livelihoods improvement: Lessons and best practices from Nepal.” USAID.

Demisu, Abebe. 2013. "Integration of family planning/sexual reproductive health with forest conservation enhanced active involvement of young people." Presented at the 2013 Population, Health, and Environment Conference, November 11-13, 2013.

Deribe, Shewaye. 2013. "PHE integration: Value addition to development projects and significance for climate change adaptation: Experience of Ethio Wetlands and Natural Resources Association (EWNRA)." Presented at the 2013 Population, Health, and Environment Conference, November 11-13, 2013. 
"Desk review of programs integrating family planning with food security and nutrition." 2015. FHI360 - Food and Nutrition Technical Assistance (FANTA III). Available at:

http://www.fantaproject.org/sites/default/files/resources/FANTA-PRH-FamilyPlanning-Nutrition-May2015.pdf

De Souza, Roger-Mark. 2014. "Resilience, integrated development and family planning: building long-term solutions." Reproductive Health Matters. 22(43):75-83.

Diamond, Nancy K. 2010. “Engendering conservation constituencies: Understanding the links between women's empowerment and biodiversity conservation outcomes for PHE programs."

"Empowering communities through integrated systems strengthening in northern Mozambique." 2012. Pathfinder International. Available at: http://www.pathfinder.org/publications-

tools/pdfs/Empoderando as Comunidades Atravas do Fortalecimento Integrado de Sistemas em Nampula.pd $\underline{\mathrm{e} x}=63 \& \mathrm{y}=24$

“Ethio Wetlands and Natural Resources Association (EWNRA): Outcomes and impacts.” EWNRA, June 2013.

"Facts and figures: Water, sanitation and hygiene links to health." Accessed November 19, 2014 at:

http://www.who.int/water sanitation health/publications/factsfigures04/en/

FHI 360/PROGRESS Project. 2013. Integrating family planning into other development sectors. Durham, NC: FHI 360. Available at: http://www.fhi360.org/sites/default/files/media/documents/integrating-family-planningdevelopment-sectors.pdf

"Final results of the Alam Sehat Lestari five year impact survey." Health in Harmony.

"Four Million Deaths Each Year Caused by Acute Respiratory Infections - New Atlas Details Pandemic." Accessed November 19, 2014 at http://www.worldlungfoundation.org/ht/displav/ReleaseDetails/i/12503/pid/6858

"FUNDAECO - Foundation for ecodevelopment and conservation - 1990-2011." 2011. Available at: http://www.fundaeco.org.gt/UserFiles/Downloads/Profile-Foundation-for-Ecodevelopment-and-Conservation2011.pdf

Gaffikin, Lynne, and Kalema-Zikusoka, Gladys. 2010. "Integrating human and animal health for conservation and development: Findings from a program evaluation in southwest Uganda." Conservation through Public Health, Evaluation and Research Technologies for Health, and John Snow, Inc.

Girvetz, Evan H., et al. 2014. "Bridging climate science to adaptation action in data sparse Tanzania." Environmental Conservation. 41(2): 229-238.

Gorenflo, L.J., Catherine Corson, Kenneth M. Chomitz, Grady Harper, Miroslav Honzák, and Berk Özler. 2011. "Exploring the association between people and deforestation in madagascar." Human Population; Ecological Studies. 214: 197-221.

Hahn, Sigrid, Natasha Anandaraja, and Leona D’Agnes, 2011. “Linking population, health, and the environment: An overview of integrated programs and a case study in Nepal." Mount Sinai Journal of Medicine. 78(3): 394-405.

Hardee, Karen and Clive Mutunga. 2009. "Strengthening the link between climate change adaptation and national development plans: lessons from the case of population in National Adaptation Programmes of Action (NAPAs)." Mitigation and Adaptation Strategies for Global Change. 15(2):113-126. 
Hardee, Karen. 2014. "Climate change science, policy and programming: Where are population and reproductive health?” Critical Issues in Reproductive Health, ed. A. Kulczycki, Springer series on Demographic Methods and Population Analyses. 177-193.

Harper, Grady J. et al. 2007. "Fifty years of deforestation and forest fragmentation in Madagascar." Environmental Conservation 34(4): 1-9.

Harris, Alasdair et al. 2012. "Integrating family planning service provision into community-based marine conservation.” Oryx. Flora \& Fauna International. 46(2): 179-186.

“Healthy families, healthy forests: Improving human health and biodiversity conservation.” 2008. Conservation International.

Hoke, Theresa H., Caroline Mackenzie, Gwyneth Vance, Brooke Boyer, Eva Canoutas, John Bratt, Agatha Mbulo and Nancy Waceke. 2015. "Integrating family planning promotion into the work of environmental volunteers: A population, health and environment initiative in Kenya." International Perspectives on Sexual and Reproductive Health. 41(1): 43-50.

Honzak, Cara, Judy Oglethorpe, and David López-Carr. 2012. "Conservation and family planning: What is the value of integrating family planning into conservation projects?” Papers of the Population Association of America Annual Meeting 2012, May 3-5, 2012.

Honzak, Cara and Judy Oglethorpe. 2011. "Learning Brief Number 1: Conservation and family planning: What is the value of integrating family planning into conservation projects?” WWF-US.

"HoPE-LVB measures of success: Evidence of progress to date." HoPE LVB, presented on May 7, 2014 in Kisumu, Kenya.

Hughes, Ross, and Fiona Flintan. 2001. "Integrating conservation and development experience: A review and bibliography of the ICDP literature.” London: International Institute for Environment and Development.

"Integrating social, economic, and environmental resources: The contributions of the PHE approach to reproductive health in Ethiopia." Packard Foundation. Available at: http://pheethiopia.org/admin/uploads/attachment-1280-Balancing.pdf

Janha, Fatou. 2013. "Integrated programming for environmental stewardship." Presented at the 2013 Population, Health, and Environment Conference, November 11-13, 2013.

Kaaya, Christine. 2013. "Integrating PHE in rural agricultural interventions among small holder farmers: VEDCO." Presented at the 2013 Population, Health, and Environment Conference, November 11-13, 2013.

Kalema-Zikusoka, Gladys et al. 2013. "Sustaining and scaling up PHE interventions in and around national parks in Uganda." Presented at the 2013 Population, Health, and Environment Conference, November 11-13, 2013.

Kitzantides, Irene. 2010. "USAID Sustaining Partnerships to enhance Rural Enterprise and Agribusiness Development (SPREAD) Project: Integrated community health program mid-term program evaluation.” USAID.

“Making the connection: Population dynamics and climate compatible development." 2014. Population Reference Bureau. Available at: http://www.prb.org/pdf15/population-climate-brief.pdf. 
Mavanza, Mary and Amy A. Grossman. 2007. "Conservation and family planning in Tanzania: The TACARE experience.” Population and Environment. 28(4-5): 267-273.

Merlo, Dario. 2013. "Community centered conservation in eastern DRC.” Presented at the 2013 Population, Health, and Environment Conference, November 11-13, 2013.

Mogelgaard, Kathleen and Kristen P. Patterson. 2006. "Linking population, health, and environment in Fianarantosa Province, Madagascar.” Population Reference Bureau. Available at:

http://www.prb.org/pdf06/PHEMadagascar2006.pdf

Mohan, Vik, Laura Robson, and Caroline Savitzky. 2013. "Safidy community health programme: Year 6 report" (London: Blue Ventures Conservation), accessed at www.blueventures.org/conservation/community-health.html.

Mohan, Vik. 2014. "Uncovering the hidden power of population-health-environment programmes." Accessed December 8, 2014 at: http://blog.blueventures.org/uncovering-hidden-power-population-health-environmentprogrammes/.

Oglethorpe, Judy, Cara Honzak, and Cheryl Margoluis. 2008. "Healthy people, healthy ecosystems: A manual on integrating health and family planning into conservation projects." World Wildlife Fund, Washington, D.C.

Pathfinder International, The Nature Conservancy, Frankfurt Zoological Society: "Tuungane project report", November 2014 (unpublished).

Patterson, Kristen P. 2012. "Building resilience in western Tanzania: Helping human and natural communities adapt to climate change and improve their health.” The Nature Conservancy.

Patterson, Kristen P. 2008. "Champion commune: Multi-sectoral approach in Fianarantsoa Province, Madagascar." Presented January 2008 at the Santénet closeout ceremony.

Pawson, Ray and Nick Tilley. 1997. Realistic Evaluation. London: Sage.

Pawson, Ray. 2013. The Science of Evaluation: A Realist Manifesto. London: Sage.

Pielemeier, John, Lori Hunter, and Robert Layng. 2007. “Assessment of USAID’s population and environment projects and programming options." Available online at:

http://www.ehproject.org/pdf/phe/phe assessment2007.pdf

Pielemeier, John. 2005. "Review of population-health-environment programs supported by the Packard Foundation and USAID."

Pielemeier, John. 2007. "Lessons from the first generation of integrated population, health, and environment projects.” Environmental Change and Security Program, Woodrow Wilson Center, Washington, DC.

Pollnac, Richard B., et al. 2013. "Monitoring the BALANCED Philippines project: Promising results after only 18 months." Coastal Resources Center, University of Rhode Island. 29.

Rao, Vijay S. 2008. "Health and conservation in the Cardamoms in Cambodia: Lessons from the CI-CARE partnership." Conservation International, Cambodia. 
Refera, Befekadu and Dr. Million Belay. 2013. "Can integrating PHE in schools and communities bring change? The case of the Bale Community, Ethiopia." Presented at the 2013 Population, Health, and Environment Conference, November 11-13, 2013.

Salafsky, N. and R. Margoluis. 1999. "Threat reduction assessment: a practical and costeffective approach to evaluating conservation and development projects.” Conservation Biology 13: 830 - 841.

Savitzky, Caroline. 2013. "Results from six years of integrating family planning with marine conservation in southwest Madagascar." Presented at the 2013 Population, Health, and Environment Conference, November 11-13, 2013.

Scoones, Ian. 1998. "Sustainable rural livelihoods: A framework for analysis." IDS Working Paper 72. Available at: https://www.staff.ncl.ac.uk/david.harvey/AEF806/Sconnes1998.pdf

Sebert Kuhlmann, Anne, Loretta Gavin, and Christein Galavotti. 2010. "The integration of family planning with other health services: A literature review." International Perspectives on Sexual and Reproductive Health. 36(4).

Sussman, R.W. and A. Rakotozafy. 1994. "Plant diversity and structural analysis of a tropical dry forest in southwestern Madagascar. Biotropica 26: 241-254.

“The PHE Difference: Evaluation results from the GPSDO integrated project.” 2012. Guraghe People’s Self-help Development Organization and PHE Ethiopia Consortium.

“The Santénet Story: Improving health services, products, and practices in Madagascar from 2004 to 2008.” 2008. Chemonics International, Inc. Washington, DC.

Vander Veken, Luc and Baltazar Chilundo. 2013. "SCIP project in Northern Mozambique: Improving health and the environment through integrated system approaches.” Presented March 6, 2013, Woodow Wilson Center.

Vinya, Royd, Exhildah C. Kasumu, Stephen Syampungani, Concilia Monde, Robby Kasubika. 2011. "Preliminary study on the drivers of deforestation and potential for REDD + in Zambia." Consultancy report prepared for Forestry Department and FAO under the national UN-REDD+ Programme Ministry of Lands \& Natural Resources. Lusaka, Zambia.

Wallace, Annie. 2010. "Reflections on population, health, and environment projects in Ethiopia: the Packard Foundation's first 3 years investing in PHE in Ethiopia." Packard Foundation.

WHO Child Growth Standards. France: 2006. Available at: http://www.who.int/childgrowth/en/ 



\section{Appendix 1: Evidence of Population, Health, and Environment Changes by Project}
Complete
table
with
detailed
results
available
online
https:// docs.google.com/spreadsheets/d/1 cpNgCD22hJRwHr4WiY2SFscqOdsF5yFd2BbvsBxpd0Y/edit?usp=sharing

Positive change

No change or change not more significant than in RH only control sites

Not reported

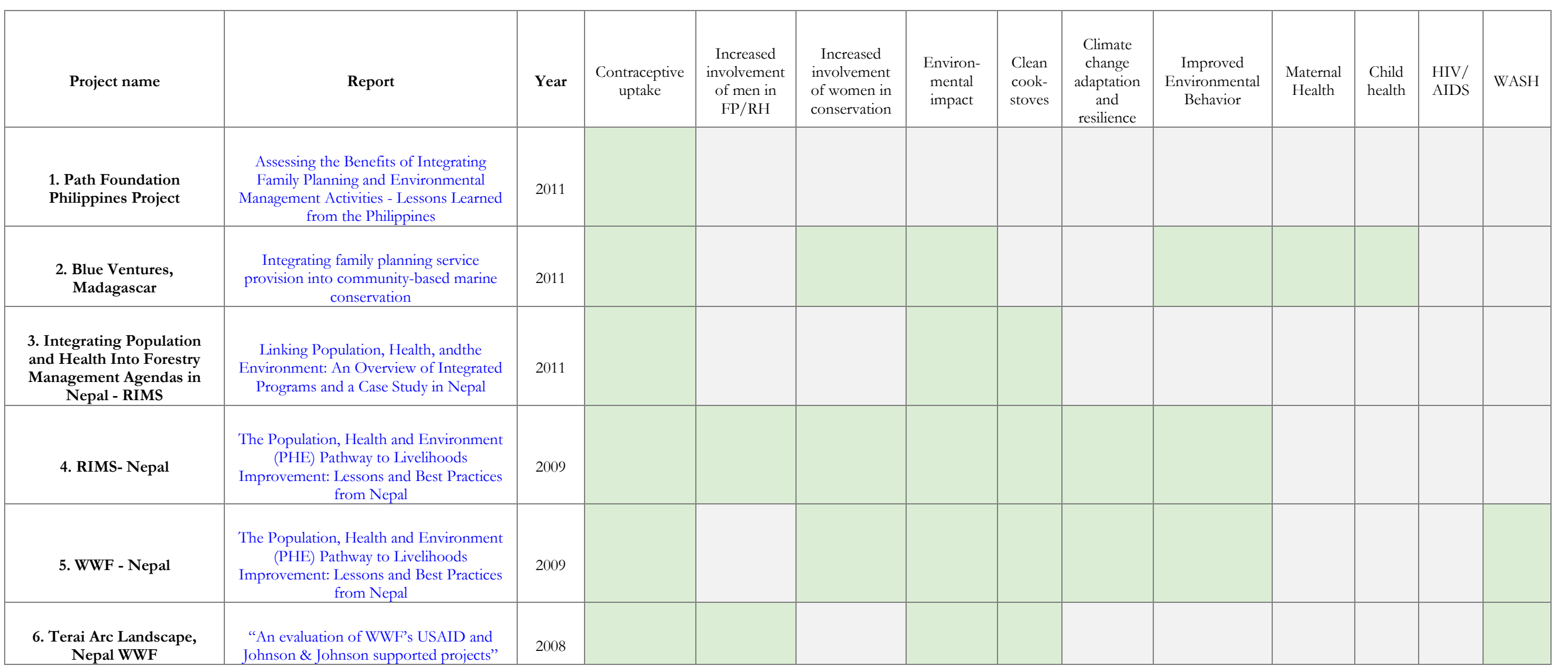




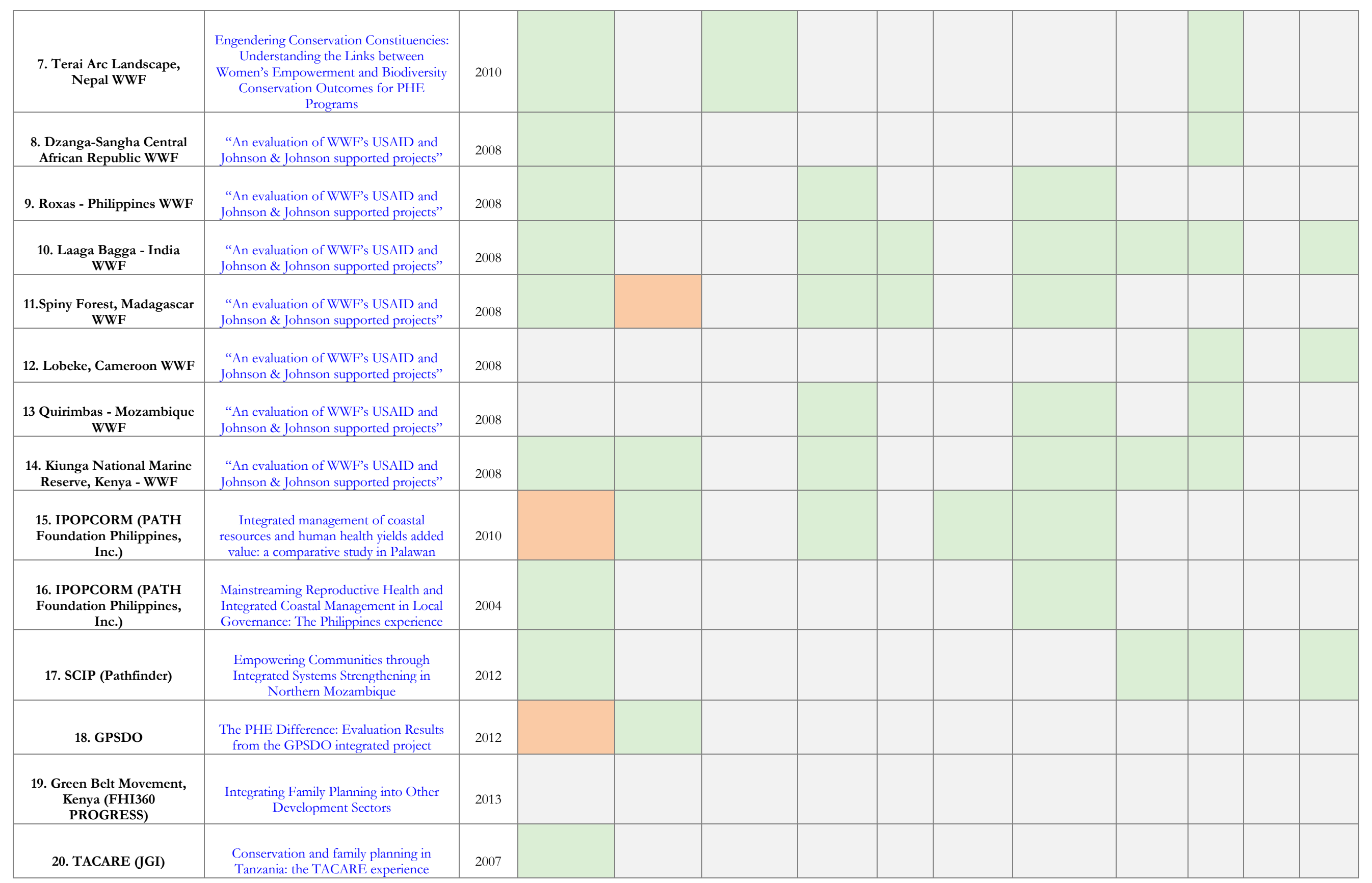

32- The Impact of Population, Health, and Environment Projects 


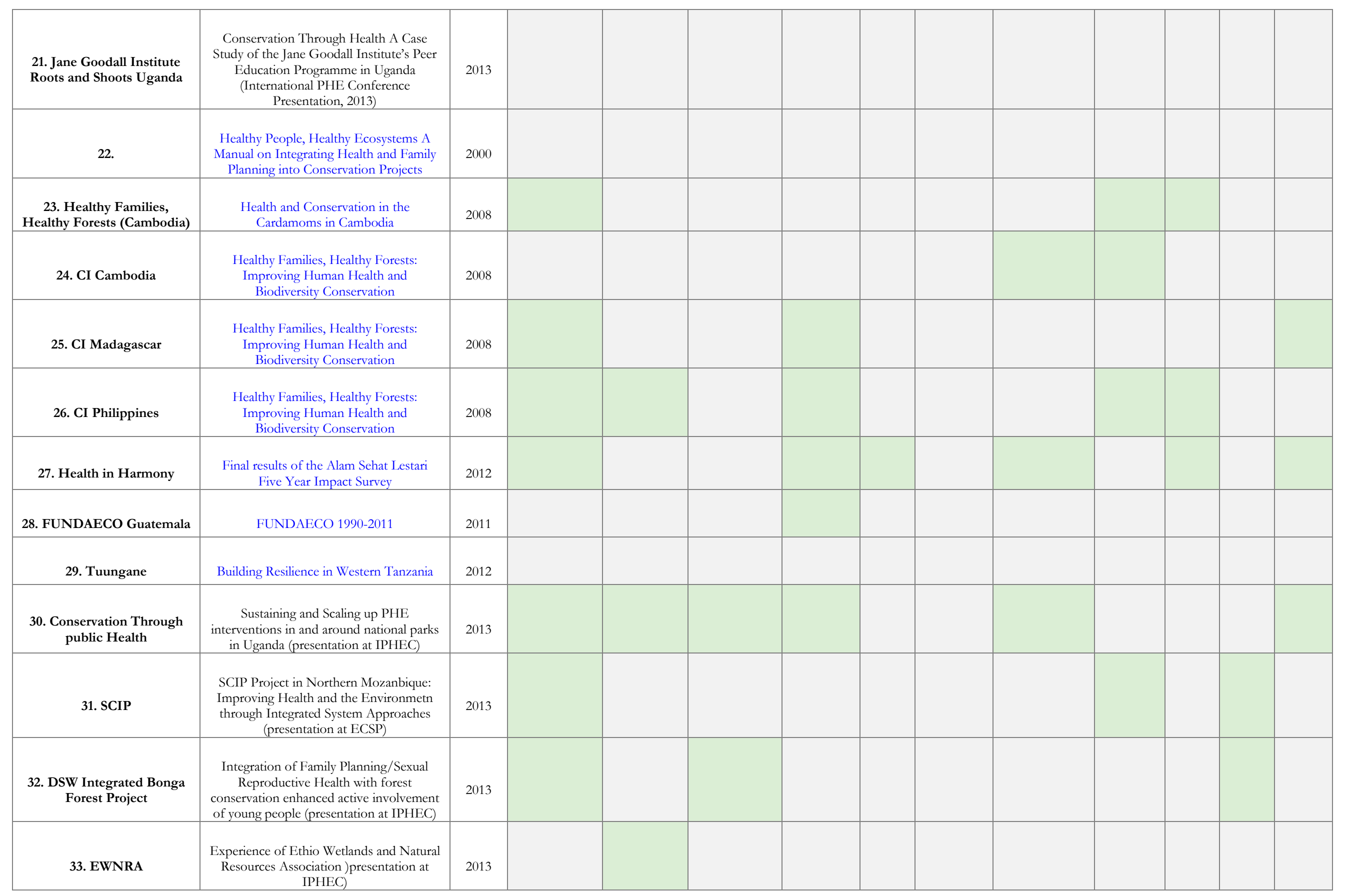




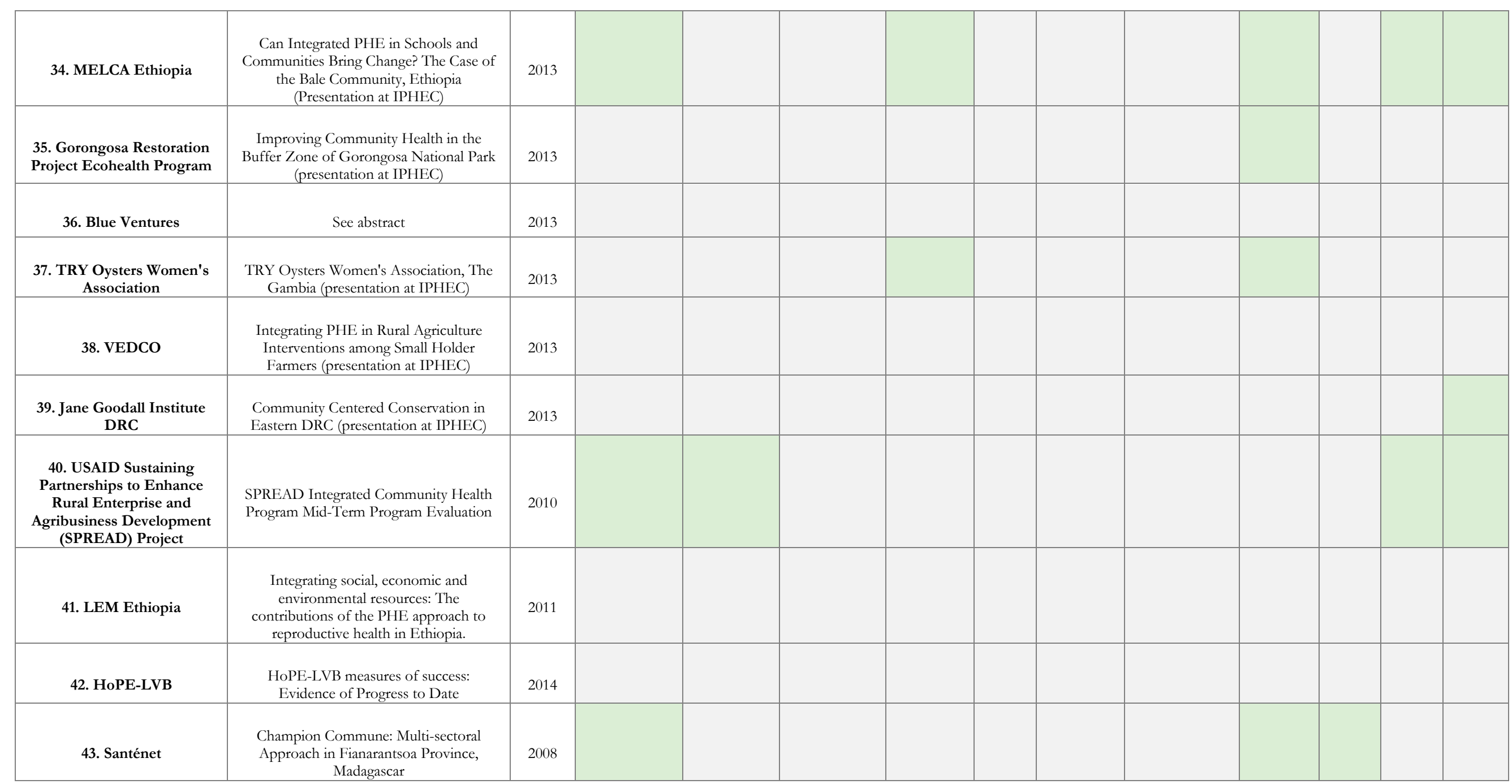




\begin{tabular}{|c|c|c|c|c|c|c|c|c|c|c|}
\hline Project Name & Report & Year & $\begin{array}{c}\text { ARI } \\
\text { Incidence }\end{array}$ & $\begin{array}{l}\text { Reaching Hard } \\
\text { to Reach } \\
\text { Communities }\end{array}$ & $\begin{array}{l}\text { Involvement } \\
\text { of Youth }\end{array}$ & $\begin{array}{l}\text { Cost- } \\
\text { Effectiveness }\end{array}$ & $\begin{array}{l}\text { Time } \\
\text { Efficiency }\end{array}$ & $\begin{array}{l}\text { More } \\
\text { Responsive to } \\
\text { Community } \\
\text { Priorities }\end{array}$ & $\begin{array}{l}\text { Alternative } \\
\text { Livelihoods }\end{array}$ & $\begin{array}{l}\text { Food } \\
\text { Security }\end{array}$ \\
\hline $\begin{array}{l}\text { 1. Path Foundation } \\
\text { Philippines Project }\end{array}$ & $\begin{array}{l}\text { Assessing the Benefits of Integrating } \\
\text { Family Planning and Environmental } \\
\text { Management Activities - Lessons Learned } \\
\text { from the Philippines }\end{array}$ & 2011 & & & & & & & & \\
\hline $\begin{array}{l}\text { 2. Blue Ventures, } \\
\text { Madagascar }\end{array}$ & $\begin{array}{c}\text { Integrating family planning service } \\
\text { provision into community-based marine } \\
\text { conservation }\end{array}$ & 2011 & & & & & & & & \\
\hline $\begin{array}{l}\text { 3. Integrating Population } \\
\text { and Health Into Forestry } \\
\text { Management Agendas in } \\
\text { Nepal - RIMS }\end{array}$ & $\begin{array}{l}\text { Linking Population, Health, andthe } \\
\text { Environment: An Overview of Integrated } \\
\text { Programs and a Case Study in Nepal }\end{array}$ & 2011 & & & & & & & & \\
\hline 4. RIMS- Nepal & $\begin{array}{l}\text { The Population, Health and Environment } \\
\text { (PHE) Pathway to Livelihoods } \\
\text { Improvement: Lessons and Best Practices } \\
\text { from Nepal }\end{array}$ & 2009 & & & & & & & & \\
\hline 5. WWF - Nepal & $\begin{array}{l}\text { The Population, Health and Environment } \\
\text { (PHE) Pathway to Livelihoods } \\
\text { Improvement: Lessons and Best Practices } \\
\text { from Nepal }\end{array}$ & 2009 & & & & & & & & \\
\hline $\begin{array}{l}\text { 6. Terai Arc Landscape, } \\
\text { Nepal WWF }\end{array}$ & $\begin{array}{l}\text { "An evaluation of WWF's USAID and } \\
\text { Johnson \& Johnson supported projects" }\end{array}$ & 2008 & & & & & & & & \\
\hline $\begin{array}{l}\text { 7. Terai Arc Landscape, } \\
\text { Nepal WWF }\end{array}$ & $\begin{array}{l}\text { Engendering Conservation Constituencies: } \\
\text { Understanding the Links between } \\
\text { Women's Empowerment and Biodiversity } \\
\text { Conservation Outcomes for PHE } \\
\text { Programs }\end{array}$ & 2010 & & & & & & & & \\
\hline $\begin{array}{l}\text { 8. Dzanga-Sangha Central } \\
\text { African Republic WWF }\end{array}$ & $\begin{array}{l}\text { "An evaluation of WWF's USAID and } \\
\text { Johnson \& Johnson supported projects" }\end{array}$ & 2008 & & & & & & & & \\
\hline 9. Roxas - Philippines WWF & $\begin{array}{l}\text { "An evaluation of WWF's USAID and } \\
\text { Johnson \& Johnson supported projects" }\end{array}$ & 2008 & & & & & & & & \\
\hline $\begin{array}{l}\text { 10. Laaga Bagga - India } \\
\text { WWF }\end{array}$ & $\begin{array}{l}\text { "An evaluation of WWF's USAID and } \\
\text { Johnson \& Johnson supported projects" }\end{array}$ & 2008 & & & & & & & & \\
\hline $\begin{array}{l}\text { 11. Spiny Forest, } \\
\text { Madagascar WWF }\end{array}$ & $\begin{array}{l}\text { "An evaluation of WWF's USAID and } \\
\text { Johnson \& Johnson supported projects" }\end{array}$ & 2008 & & & & & & & & \\
\hline
\end{tabular}




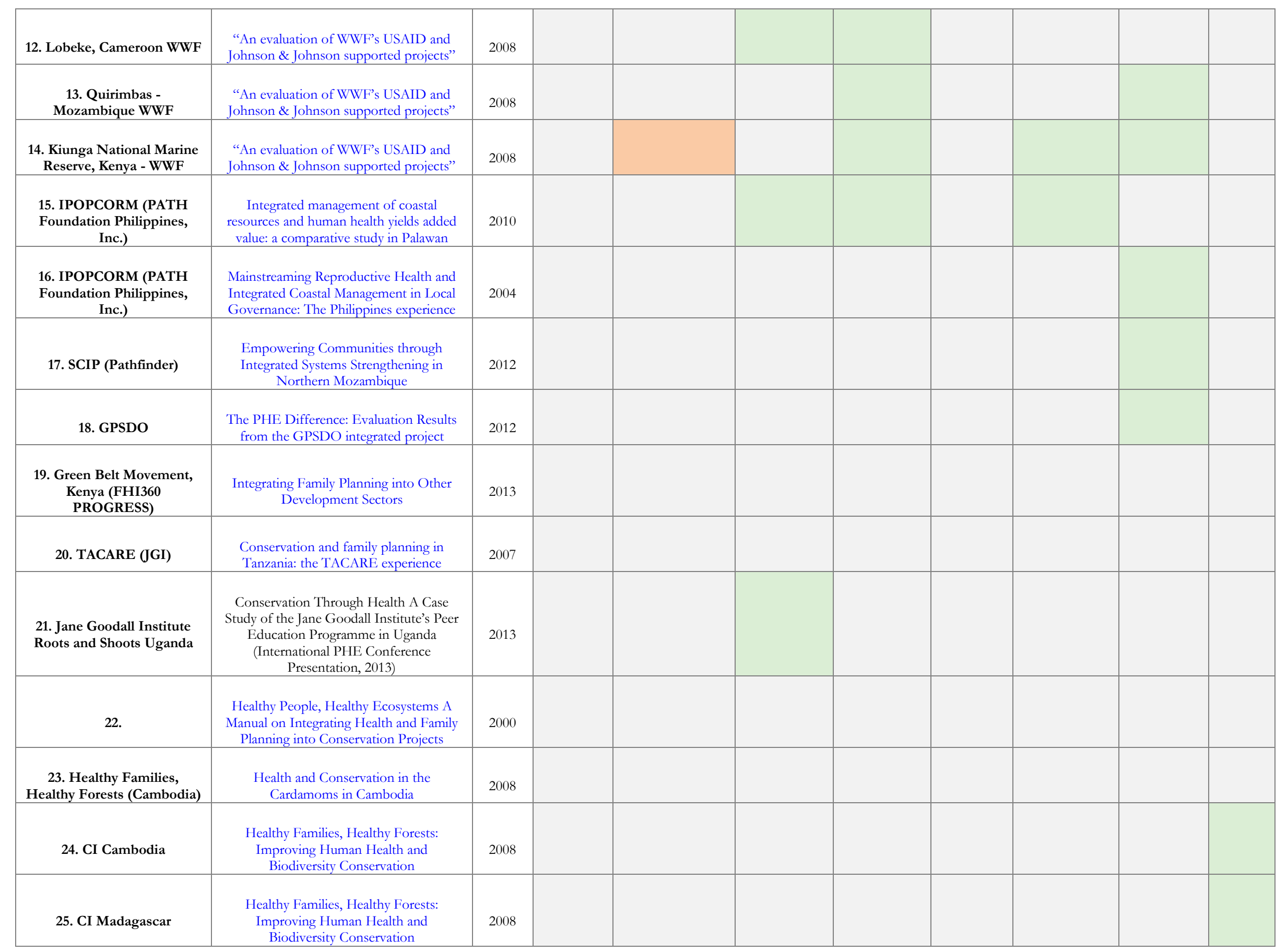

36 - The Impact of Population, Health, and Environment Projects 


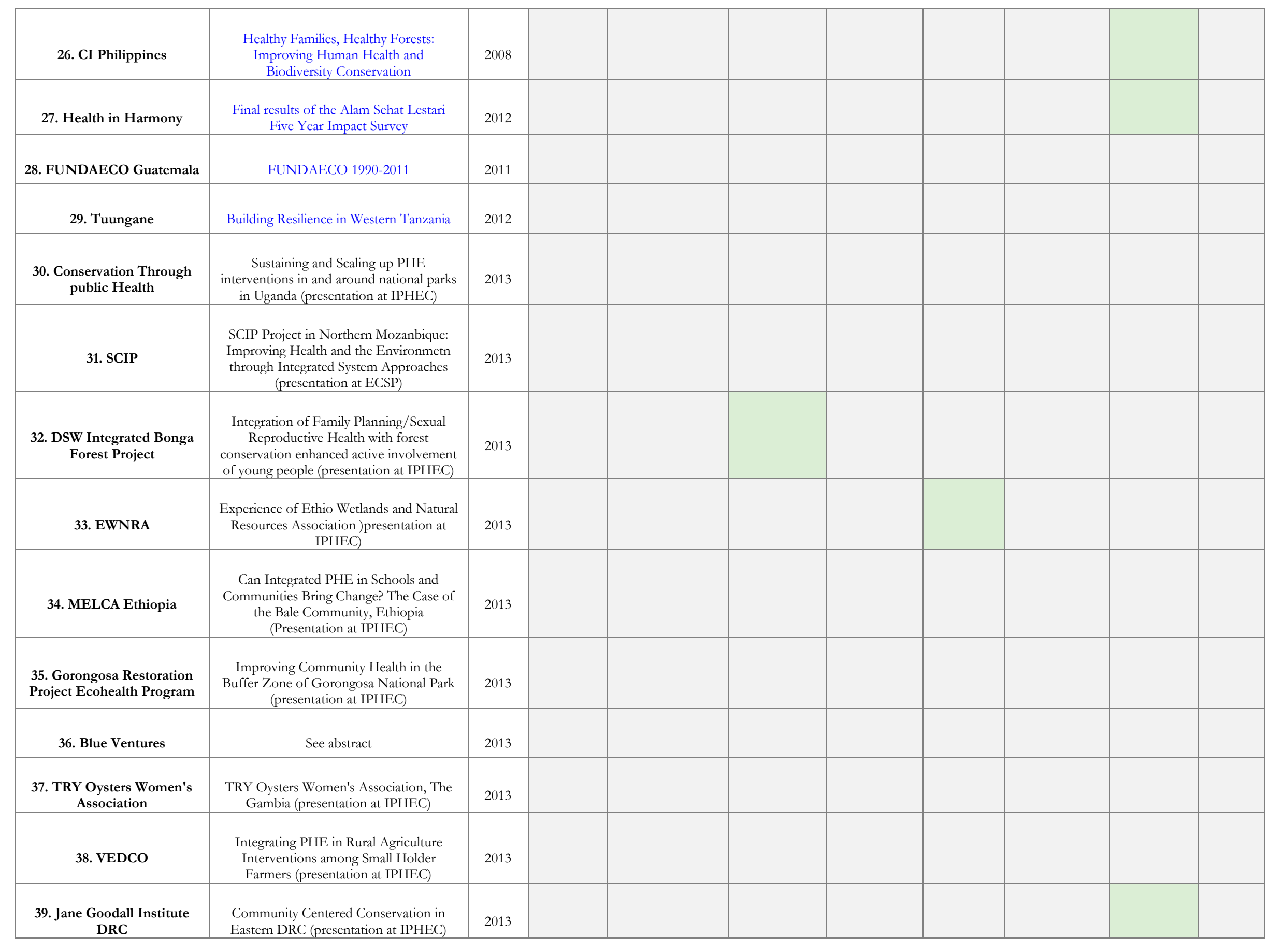




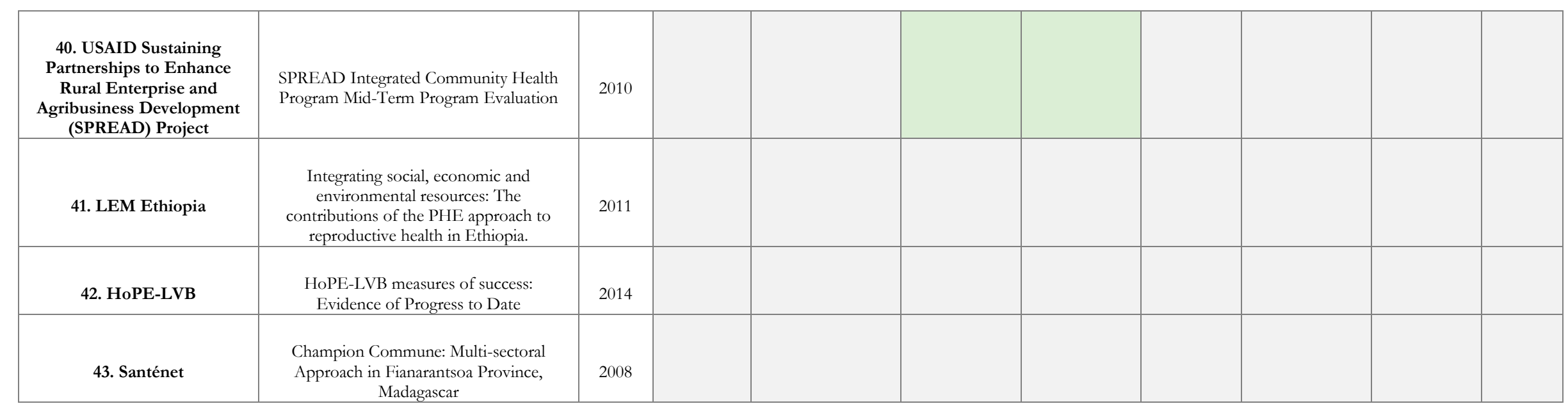





\section{The Evidence Project}

\section{Population Council}

4301 Connecticut Avenue, NW, Suite 280

Washington, DC 20008 USA

tel +12022379400

evidenceproject.popcouncil.org 